\title{
Modeling the elastic transmission of tidal stresses to great distances inland in channelized ice streams
}

\author{
J. Thompson, M. Simons, and V. C. Tsai \\ Seismological Laboratory, Division of Geological and Planetary Sciences, California Institute of Technology, MC 252-21, \\ 1200 E. California Blvd., Pasadena, CA 91125, USA
}

Correspondence to: J. Thompson (jeffremt@gmail.com)

Received: 21 February 2014 - Published in The Cryosphere Discuss.: 25 April 2014

Revised: 18 September 2014 - Accepted: 22 September 2014 - Published: 5 November 2014

\begin{abstract}
Geodetic surveys suggest that ocean tides can modulate the motion of Antarctic ice streams, even at stations many tens of kilometers inland from the grounding line. These surveys suggest that ocean tidal stresses can perturb ice stream motion at distances about an order of magnitude farther inland than tidal flexure of the ice stream alone. Recent models exploring the role of tidal perturbations in basal shear stress are primarily one- or two-dimensional, with the impact of the ice stream margins either ignored or parameterized. Here, we use two- and three-dimensional finiteelement modeling to investigate transmission of tidal stresses in ice streams and the impact of considering more realistic, three-dimensional ice stream geometries. Using Rutford Ice Stream as a real-world comparison, we demonstrate that the assumption that elastic tidal stresses in ice streams propagate large distances inland fails for channelized glaciers due to an intrinsic, exponential decay in the stress caused by resistance at the ice stream margins. This behavior is independent of basal conditions beneath the ice stream and cannot be fit to observations using either elastic or nonlinear viscoelastic rheologies without nearly complete decoupling of the ice stream from its lateral margins. Our results suggest that a mechanism external to the ice stream is necessary to explain the tidal modulation of stresses far upstream of the grounding line for narrow ice streams. We propose a hydrologic model based on time-dependent variability in till strength to explain transmission of tidal stresses inland of the grounding line. This conceptual model can reproduce observations from Rutford Ice Stream.
\end{abstract}

\section{Introduction}

\subsection{Relevant observations}

Observations from some Antarctic ice streams show tidally modulated surface displacements extending many tens of kilometers inland of the grounding line (see Fig. 1, Table 1, and associated references). Geodetic and seismic observations that probe the interaction between ocean tides and ice stream motion include surface tilt (tiltmeters), differential position (synthetic aperture radar, InSAR), absolute position (altimetric surveys and global positioning system, GPS), and basal seismicity (see Table 1). When such observations are found to fluctuate at tidal or near-tidal frequencies, they can be used to estimate the spatial extent of ocean tidal influences on the flow of ice streams (see, for example, references described below).

Surface tilt surveys quantify the maximum extent of the flexure of an ice body due to the tides (the "hinge line"). For relevant ice streams (see Table 1), the hinge line is found between 5 and $10 \mathrm{~km}$ inland of the grounding line (e.g., Rignot, 1998). Seismic studies on several Siple Coast ice streams correlate fluctuations in basal seismicity with the semidiurnal and/or fortnightly ocean tides, suggesting a link between ocean tidal loading and basal stress in these ice streams (Harrison et al., 1993; Anandakrishnan and Alley, 1997; Bindschadler and et al., 2003; Wiens et al., 2008; Walter et al., 2011). Furthermore, continuous GPS (CGPS) surveys on some Antarctic ice streams find surface velocities modulated at tidal frequencies (Rutford Ice Stream: Gudmundsson, 2006, 2007; Bindschadler Ice Stream: Anandakrishnan et al., 2003) or stick-slip motion correlated with extremes in 
Table 1. Spatial extent of observations suggesting tidal modulation of ice stream motion and ice flexure from selected ice streams across Antarctica.

\begin{tabular}{|c|c|c|c|c|}
\hline \multirow[b]{2}{*}{ Region } & \multicolumn{2}{|c|}{ Tidally modulated observations } & \multicolumn{2}{|c|}{ Ice flexure } \\
\hline & $\begin{array}{r}\text { Extent } \\
(\mathrm{km})\end{array}$ & Method & $\begin{array}{l}\text { Extent } \\
(\mathrm{km})\end{array}$ & Method \\
\hline Bindschadler & $80+$ & GPS $^{1}$ & $\sim 10$ & Altimetry $^{2}$ \\
\hline Ekström & $<3$ & GPS $^{3}$ & $\sim 5$ & Tilt $^{3}$ \\
\hline Kamb & $85+$ & Seismicity ${ }^{4}$ & $\sim 10$ & Altimetry $^{2}$ \\
\hline Pine Island & $<55$ & $\mathrm{GPS}^{5}$ & $\sim 5$ & $\mathrm{SAR}^{6}$ \\
\hline Rutford & $40+$ & $\mathrm{GPS}^{7,8}$ & $5+$ & Tilt $^{9}$ \\
\hline Whillans Ice Plain & $\sim 100$ & GPS and seismicity $10,11,12,13$ & $\sim 10$ & Altimetry $^{2}$ \\
\hline Whillans Ice Stream & $\sim 300$ & Seismicity ${ }^{14}$ & N/A & Altimetry $^{2}$ \\
\hline
\end{tabular}

Superscript numbers denote the following references: ${ }^{1}$ Anandakrishnan et al. (2003); ${ }^{2}$ Brunt et al. (2010); ${ }^{3}$ Heinert and Riedel (2007); ${ }^{4}$ Anandakrishnan and Alley (1997); ${ }^{5}$ Scott et al. (2009); ${ }^{6}$ Rignot (1998); ${ }^{7}$ Gudmundsson (2006);

${ }^{8}$ Gudmundsson (2007); ${ }^{9}$ Stephenson (1984); ${ }^{10}$ Weins and et al. (2008); ${ }^{11}$ Winberry et al. (2009); ${ }^{12}$ Walter et

al. (2011); ${ }^{13}$ Winberry et al. (2014); ${ }^{14}$ Harrison et al. (1993).

tidal amplitudes (Whillans Ice Stream: Wiens et al., 2008; Winberry et al., 2009, 2014).

However, not all Antarctic ice streams exhibit a strong connection between ocean tidal loading and ice stream flow. CGPS observations on Pine Island Glacier, for example, show no tidal variability in surface motion at stations 55, 111,169 , and $171 \mathrm{~km}$ inland of the grounding line (Scott et al., 2009). Ekström Ice Stream has an even tighter constraint on the spatial extent of tidal perturbations: CGPS recordings show no measurable motion at tidal frequencies only $1 \mathrm{~km}$ inland of the grounding line (Riedel et al., 1999; Heinert and Riedel, 2007).

\subsection{Previous relevant modeling}

Many models have been proposed to explain the influence that ocean tides have on the motion of some Antarctic ice streams (e.g., Anandakrishnan and Alley, 1997; Bindschadler et al., 2003; Gudmundsson, 2006, 2007, 2011; Sergienko et al., 2009; Walker et al., 2012; Winberry et al., 2009). Given that the Maxwell relaxation time (viscosity / elastic modulus) for ice is on the order of a few hours for tidal loads, these models generally model either elastic or viscoelastic transmission of ocean tidal stresses through the ice stream inland of the grounding line - referred to as "stress transmission" in this manuscript.

We discuss several representative published models to highlight common assumptions made about the upstream transmission of tidal stresses. A standard model for ice streams is a flow-line model - a two-dimensional (2-D) cross section with transverse stresses either neglected or parameterized. When basal shear stress is averaged over the length of the ice stream, the model reduces to the one-dimensional (1-D) formulation of Bindschadler et al. (2003) and Winberry et al. (2009). These models assume that tidal stress is uniformly distributed over, and completely supported by, the ice

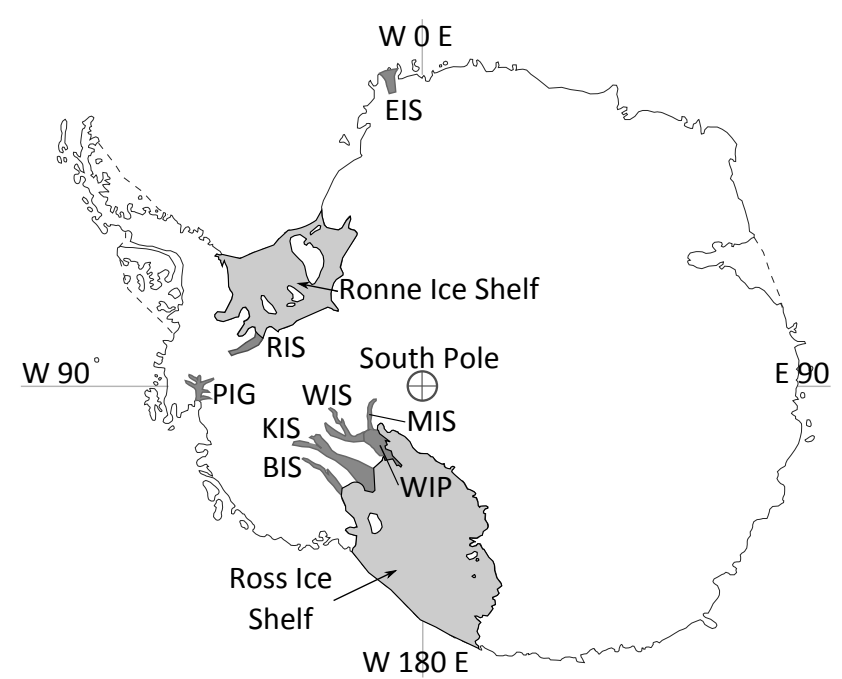

Figure 1. Map of Antarctica indicating locations of the ice streams discussed in this paper (BIS - Bindschadler Ice Stream; EIS Ekström Ice Stream; KIS - Kamb Ice Stream; PIG - Pine Island Glacier; RIS - Rutford. Ice Stream; WIP - Whillans Ice Plain; WIS - Whillans Ice Stream; MIS - Mercer Ice Stream).

stream's bed. In this type of model, the distance inland to which a tidal stress propagates depends completely on the assumed length of the ice stream.

Finite-element analysis in 2-D allows for flow-line models with increased complexity and more realistic geometries. An applicable model of tidal stress propagation is that of Gudmundsson (2011). This 2-D flow-line model incorporates nonlinear ice viscoelasticity and a nonlinear basal sliding law. In Gudmundsson's (2011) analysis, the response of the modeled ice stream relates directly to the basal boundary condition. Such a result is intuitive as lateral resistance from the ice stream's margins is neglected, and thus the tidal load 

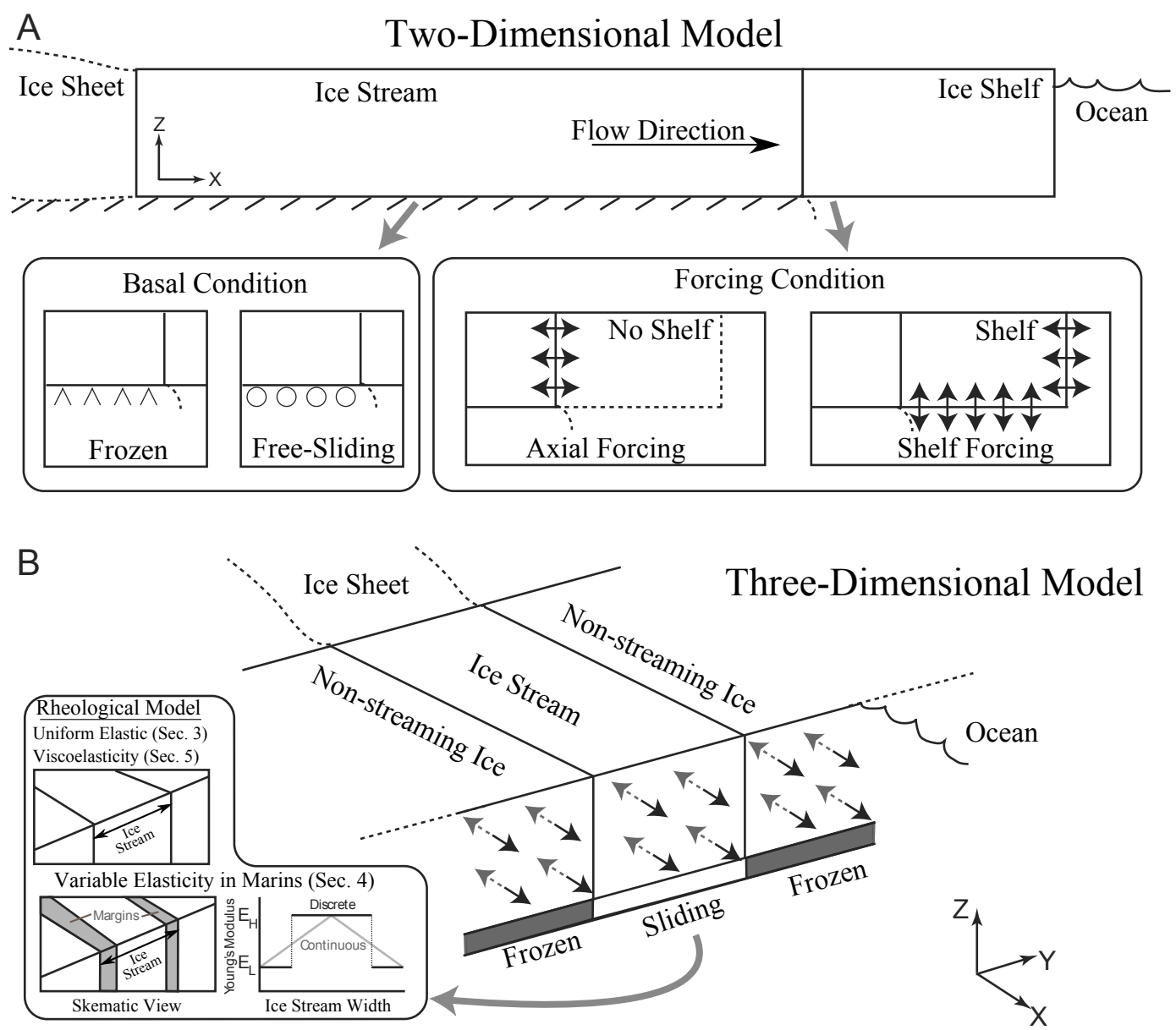

Figure 2. Schematics of the models described in this paper. Inset boxes show options used in each model. For the 2-D models, these options are either a frozen $\left(u_{x}=u_{z}=0\right)$ or free-sliding $\left(u_{z}=0\right)$ basal condition with or without an ice shelf. For the 3-D models, we use the same model geometry with variable rheologies: homogeneous linear elasticity, marginal regions of variable elasticity, or Glen-style viscoelasticity.

must necessarily be controlled by the basal rheology of the ice stream. This type of model is attractive as the basal rheologies can be tuned to accurately match observations. However, the fact that these models can be made to fit the observations does not demonstrate that lateral resistance in these ice streams is indeed negligible. Note that a three-dimensional (3-D) version of Gudmundsson's model is currently in review and is publically available online for viewing (Rosier et al., 2014). This 3-D model will be discussed in Sect. 6.1.

Alternatively, Sergienko et al. (2009) approximated an ice stream as a series of masses (blocks) connected elastically (by springs) and restrained laterally (by further springs) with a shear stress applied along a frictional basal contact. Unlike the previous 2-D models, this spring-block model does incorporate the lateral resistance of the ice margins. Sergienko et al. (2009) note that a "tidal" load applied at one edge in this model diminishes with distance from the loaded block, but this stress decay is not explored in further detail. We assume that this distance depends on the stiffness of the springs, both between the masses and as lateral restraints, as well as the magnitude of the basal friction imposed in the model. However, there is no obvious relation between a physical length scale and the number of blocks and springs in the model. Additionally, it is not clear if the decay of the tidal stress is caused by marginal or basal resistance in this model.

\section{Methodology}

In this manuscript, we present results from 2-D and 3-D models that explore the role that ice stream geometry plays in controlling transmission of tidal stresses. We describe our models below and show them schematically in Fig. 2. We then expand our homogeneous elastic models to incorporate shear-weakened margins (Sect. 4) and viscoelasticity (Sect. 5).

We start with a 2-D finite-element flow-line model of an elastic ice stream (Fig. 2a) to benchmark the computational models and to establish the extremes for stress transmission of an applied tidal load. An underlying assumption of this 
2-D model is that the ice stream is infinite and uniform in the third dimension, such that there effectively are no lateral margins to the ice stream. These simplified models allow us to establish "end-member" behavior of an elastic ice stream by applying the extreme basal conditions of either a frozen (no slip) or a free-sliding (no shear traction) bed. Additionally, we use these 2-D models to investigate the role played by an ice shelf as an intermediary between the ocean tides and the grounded ice stream.

Based on the intuition gained from these 2-D models, we then explore a series of 3-D models (Fig. 2b) to study the impact of resistive shearing at the lateral margins of the model on the inland transmission of an applied tidal load. We first investigate the role that the overall geometry of the ice stream (i.e., ice stream width and thickness) has on the transmission of tidal stresses inland of the grounding line. From these models, we find that including the lateral margins of the ice stream inherently limits the distances to which tidal stress are transmitted inland. For narrow (channelized) ice streams, the inland transmission of a tidal load is found to be too small to be consistent with observations, even in the case of frictionless sliding at the bed (Sect. 3).

In the second part of this paper, we consider two mechanisms for decoupling the model ice stream from its lateral margins. First, we investigate the potential for "weakened" ice in the margins to reduce the lateral resistance to the inland transmission of a tidal stress (Sect. 4). Second, we investigate the effect that using a Glen-style viscoelasticity for ice may have on the transmission of tidal stresses inland of the grounding line (Sect. 5). Modeling methodologies for these models are presented in their corresponding section.

Comparing model results to tidally modulated GPS data from Rutford Ice Stream, we establish that we cannot match observations using a model that assumes tidal loads are transmitted through the bulk of an ice stream, even after accounting for potential decoupling mechanism (Sects. 4 and 5). We conclude with a model suggesting subglacial hydrology as a potential explanation for transmission of tidal stresses inland of the grounding line (Sect. 6.3).

\subsection{Model construction}

Our calculations rely on the finite-element modeling (FEM) software PyLith (Williams et al., 2005; Williams, 2006; Aagaard et al., 2007, 2008, 2011) for our numerical modeling. This open-source Lagrangian FEM code has been developed and extensively benchmarked in the crustal deformation community (available at www.geodynamics.org/pylith). PyLith solves the conservation of momentum equations with an associated rheological model. As we assume a quasistatic formulation (i.e., all inertial terms are dropped), the governing equations are $\sigma_{i j, j}=f_{i}$ in $V$

$\sigma_{i j} n_{j}=T_{i}$ on $S_{T}$

$u_{i}=u_{i}^{0}$ on $S_{U}$,

where $V$ is an arbitrary body with boundary conditions on surfaces $S_{T}$ and $S_{U}$. On $S_{T}$, the traction $\sigma_{i j} n_{j i}$ is set equal to the applied Neumann boundary condition $T_{i}$. On $S_{U}$, the displacement $u_{i}$ is set equal to the applied Dirichlet boundary condition $u_{i}^{0}$.

PyLith solves these governing equations using a Galerkin formulation of the spatial equations and an unconditionally stable method of implicit time stepping for both an elastic and viscoelastic rheology (following the form of Bathe, 1995). For model convergence, we select a tolerance of 1e12 in the absolute residual of the iterative solver from the PETSc library (Balay et al., 1997, 2012a, b) and a relative tolerance to the initial residual value of $1 \mathrm{e}-8$. Based on several experiments, these values are sufficiently conservative to ensure solution convergence without causing a prohibitive increase in computational time.

\subsubsection{Model geometry}

For the models discussed here, the finite-element model geometry is intentionally kept as simple as possible (Fig. 2). 2D models are considered with and without an ice shelf, while the 3-D models do not include an ice shelf. As described in Appendix A, our 2-D model results show that the ice shelf can be safely neglected as the ice shelf does not influence the length scale of stress transmission far inland of the grounding line.

In our 2-D models, we consider only the thickness $(Z)$ to be limiting, while the model length $(X)$ is not. We use a geometry long enough that changes to the length have a negligible effect on the model results (i.e., the $X$ dimension is "pseudo-infinite"). For our 3-D models, only the thickness $(Z)$ and width $(Y)$ of the ice stream are limiting dimensions. The length of the ice stream $(X)$ and the widths of the non-streaming ice $(Y)$ are large enough to be pseudo-infinite.

We construct the FEM meshes using the software Trelis (available from http://www.csimsoft.com). For the 2-D models, we use linear isoparametric triangular elements, while we use linear isoparametric quadrilateral elements for the 3$\mathrm{D}$ models. We manually refine the meshes near regions of applied stresses, changes in boundary conditions, and material property variations. In such locations the mesh spacing can be as small as $1 \mathrm{~m}$, resulting in meshes with between $10^{5}$ and $10^{6}$ elements. To ensure that the model results are independent of the meshing scheme, we check all model results against meshes that are uniformly refined by a factor of 2 . We only present results from meshes that have less than a $0.1 \%$ change in displacement, first strain invariant, and second deviatoric stress invariant upon this refinement in our elastic models and less than $1 \%$ in our viscoelastic models. 


\subsubsection{Linear elastic rheology}

Our first models assume a linear isotropic elastic rheology for ice, with the constitutive equation taking the familiar form of Hooke's Law in three dimensions:

$\boldsymbol{C}_{i j k l}=\lambda \delta_{i j} \delta_{k l}+\mu\left(\delta_{i k} \delta_{j l}+\delta_{i l} \delta_{j k}\right)$.

We summarize model rheologic parameters, taken from Petrenko and Whitford (2002) and Cuffey and Paterson (2010), in Table 2. We assume that the Poisson's ratio is well known for ice (and thus is fixed) when exploring the ranges in values of the other elastic moduli.

\subsection{Applied boundary conditions}

This section describes the boundary conditions applied to our 2-D and 3-D models. Given the models' simplified geometries, it is convenient to refer to the edges (2-D) or faces (3-D) of the model domains by their normal vectors when describing the locations of applied boundary conditions. For example, the right edge of the 2-D model is the $X+$ edge and the top face of the $3-\mathrm{D}$ model is the $Z+$ face.

\subsubsection{Two-dimensional models}

In our 2-D models, we have two boundary conditions to consider: the basal condition of the ice stream and the loading condition of the ocean tides on the ice stream-ice shelf system. We explore two limiting basal boundary conditions: a frozen bed and a free-sliding bed. The frozen-bed condition is applied as a Dirichlet condition with zero displacements in all directions $\left(u_{x}=u_{z}=0\right)$ on the $Z$ - edge of the ice stream. The free-sliding-bed condition has a mixed boundary condition applied to the $Z$ - edge of the ice stream with zero vertical displacements $\left(u_{z}=0\right)$ and zero shear traction $\left(\sigma_{x z}=0\right)$.

Tidal loading is applied as an edge-normal Neumann (stress) boundary condition with magnitude $\sigma_{\text {normal }}=\rho g \Delta h$, where $\rho$ is the density of water, $g$ is gravitational acceleration, and $\Delta h$ is the amplitude of the tide. For models without an ice shelf, tidal loading is applied on the $X+$ edge of the model ice stream (i.e., vertical face above the grounding line). For models with a portion of the model domain representing an ice shelf, the tidal loading condition is applied along the $X+$ and $Z$ - edges of the model ice shelf. At the basal node where the ice stream and ice shelf coincide (i.e., the model's grounding line), the ice stream's basal condition is applied. Note that this approach does not apply a flotation condition to the ice shelf, and it thus assumes that there is no grounding line migration. Appendix B discusses the implications of using this method to approximate tidal loading on an ice shelf.

\subsubsection{Three-dimensional model}

We have three boundary conditions to consider in our 3D models: the basal condition of the ice stream, the basal
Table 2. Elastic and viscous parameters used to define ice properties in our finite element model. Values of elastic parameters are from Petrenko and Whitford (2002) using data from Gammon et al. (1983a, b). Viscous parameters are taken from Cuffey and Paterson (2010). Temperature-dependent viscosity coefficients are not summarized here but can be found in Cuffey and Paterson (2010). Parameters marked with an asterisk $\left(^{*}\right)$ denote quantities that are derived from the other moduli and material properties. Parameters annotated with a plus $(+)$ are fixed for all models.

\begin{tabular}{lcl}
\hline Parameter & Symbol & Value \\
\hline Young's modulus & $E$ & $9.33 \mathrm{GPa}$ \\
Poisson's ratio $^{+}$ & $v$ & 0.325 \\
Shear modulus* $^{*}$ & $G$ & $3.52 \mathrm{GPa}$ \\
Bulk modulus* & $K$ & $8.90 \mathrm{GPa}$ \\
Density (at $\left.0^{\circ} \mathrm{C}\right)^{*}$ & $\rho$ & $917 \mathrm{~kg} \mathrm{~m}$ \\
Viscosity coefficient $\left(\text { at } 0^{\circ} \mathrm{C}\right)^{+}$ & $A$ & $5.86 \times 10^{-6} \mathrm{MPa}^{-3} \mathrm{~s}^{-1}$ \\
Stress exponent $^{+}$ & $n$ & 3 \\
\hline
\end{tabular}

condition of the non-streaming ice, and the tidal loading condition. Recall from Sect. 2.1.1 that the geometry of the 3D models has a box-shaped ice stream in contact with nonstreaming ice on its $Y+$ and $Y$ - faces (see Fig. 2b).

The basal boundary condition applied to the ice stream is a 3-D version of the earlier free-sliding-bed condition. Along the $Z$ - face of the ice stream, a mixed boundary condition is applied that has zero vertical displacements $\left(u_{z}=0\right)$ and zero vertical shear tractions $\left(\sigma_{x z}=\sigma_{y z}=0\right)$. As will be discussed later, our 3-D models do not currently incorporate basal friction beneath the ice stream.

The basal boundary condition applied to the nonstreaming ice is a 3-D version of the earlier frozen-bed condition. Along the $Z-$ face of the non-streaming ice, a Dirichlet condition is applied that fixes all displacements to zero $\left(u_{x}=u_{y}=u_{z}=0\right)$. Along the $Y+$ and $Y$ - edges of the $Z-$ of the ice stream (i.e., the basal nodes shared by the ice stream and the non-streaming ice) the non-streaming ice's basal boundary condition is applied.

Similar to the 2-D models, tidal loading is applied as a face-normal Neumann (stress) condition with magnitude $\sigma_{\text {normal }}=\rho g \Delta h$. As our 3-D models have no ice shelf (see Sect. 2.1.1 and Appendix A), the tidal loading condition is applied to the $X+$ face of the ice stream and the nonstreaming ice (i.e., on the face above the model's grounding line). For models using a linear elastic approximation for ice, we do not apply a time-varying load as the model solution must necessarily vary linearly with the magnitude of the applied stress.

\subsubsection{Gravity}

Due to the superposition property of a linear elastic model, we choose to neglect the effect of gravity as a body force by setting $f_{i}$ in Eq. (1) equal to 0 , effectively neglecting the background flow of the ice stream. 


\section{D Model with Free-Sliding Bed}

A
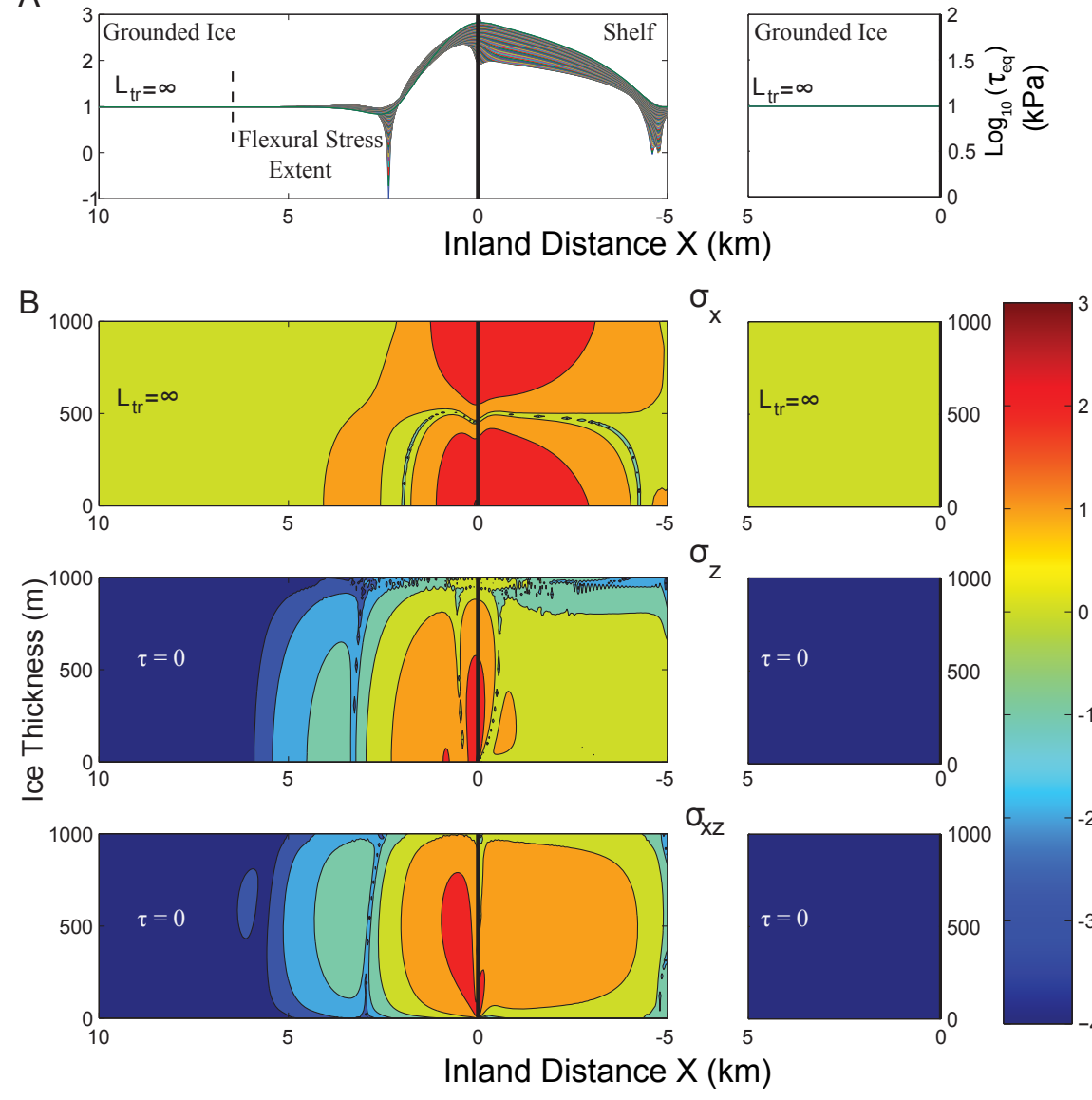

Figure 3. Distributions of stress for a 2-D model with a free-sliding basal condition. (a) shows longitudinal profiles of $\sigma_{\mathrm{eq}}$ at a depth interval of $10 \mathrm{~m}$, while (b) shows the logarithm of the absolute value of the three in-plain stress components $\left(\sigma_{x}, \sigma_{y}\right.$, and $\left.\sigma x y\right)$ for the entire 2-D model domain. Model results are shown including (left panels) and not including (right panels) an ice shelf. In the free-sliding models, axial stress does not decay with distance and flexural stress rapidly decays near the grounding line. $L_{\mathrm{tr}}$ is the stress transmission length scale as defined in Sect. 3.1.

\section{Results}

PyLith calculates the stress tensor, strain tensor, displacement vector, and velocity vector at every node of the model mesh. While we use results from close to 40 models in this manuscript, we only show visualizations of representative results; however, we include tabulated results from all models. To aid in comparing the magnitude of stress between models, we define an equivalent stress, $\tau_{\text {eq }}$, based on the von Mises criterion. $\tau_{\mathrm{eq}}$ is defined in 2-D and 3-D as

$$
\begin{aligned}
& \text { 2-D : } \tau_{\mathrm{eq}}^{2}=\frac{1}{2}\left[\left(\sigma_{x x}-\sigma_{y y}\right)^{2}+\sigma_{x x}^{2}+\sigma_{y y}^{2}+6 \sigma_{x y}^{2}\right] \\
& \text { 3-D : } \tau_{\mathrm{eq}}^{2}=\frac{1}{2}\left[\left(\sigma_{x x}-\sigma_{y y}\right)^{2}+\left(\sigma_{y y}-\sigma_{z z}\right)^{2}\right. \\
& \left.+\left(\sigma_{x x}-\sigma_{z z}\right)^{2}+6\left(\sigma_{x y}^{2}+\sigma_{y z}^{2}+\sigma_{x z}^{2}\right)\right] .
\end{aligned}
$$

\subsection{Two-dimensional results}

We begin by considering the distribution of stress in the 2-D models with free-sliding and frozen basal boundary conditions. Figures 3 and 4 present stress distributions for $1 \mathrm{~km}$ thick models using each boundary condition with and without an ice shelf. In these figures, we show longitudinal profiles of $\tau_{\text {eq }}$ taken at different depths. It is convenient to define a stress decay length scale, $L_{\mathrm{tr}}$, as the distance inland of the grounding line over which the amplitude of a tidal stress drops by an order of magnitude. Table 3 summarizes $L_{\text {tr }}$ for all stress components for the four models shown in Figs. 3 and 4. Other model geometries considered, but not explicitly discussed here, include 2 and $3 \mathrm{~km}$ thick models and models with elastic moduli 1 order of magnitude larger and smaller than the canonical value of $9.33 \mathrm{GPa}$ (see Table 4 for a summary of 2-D model results). 


\section{D Model with Frozen Bed}

A
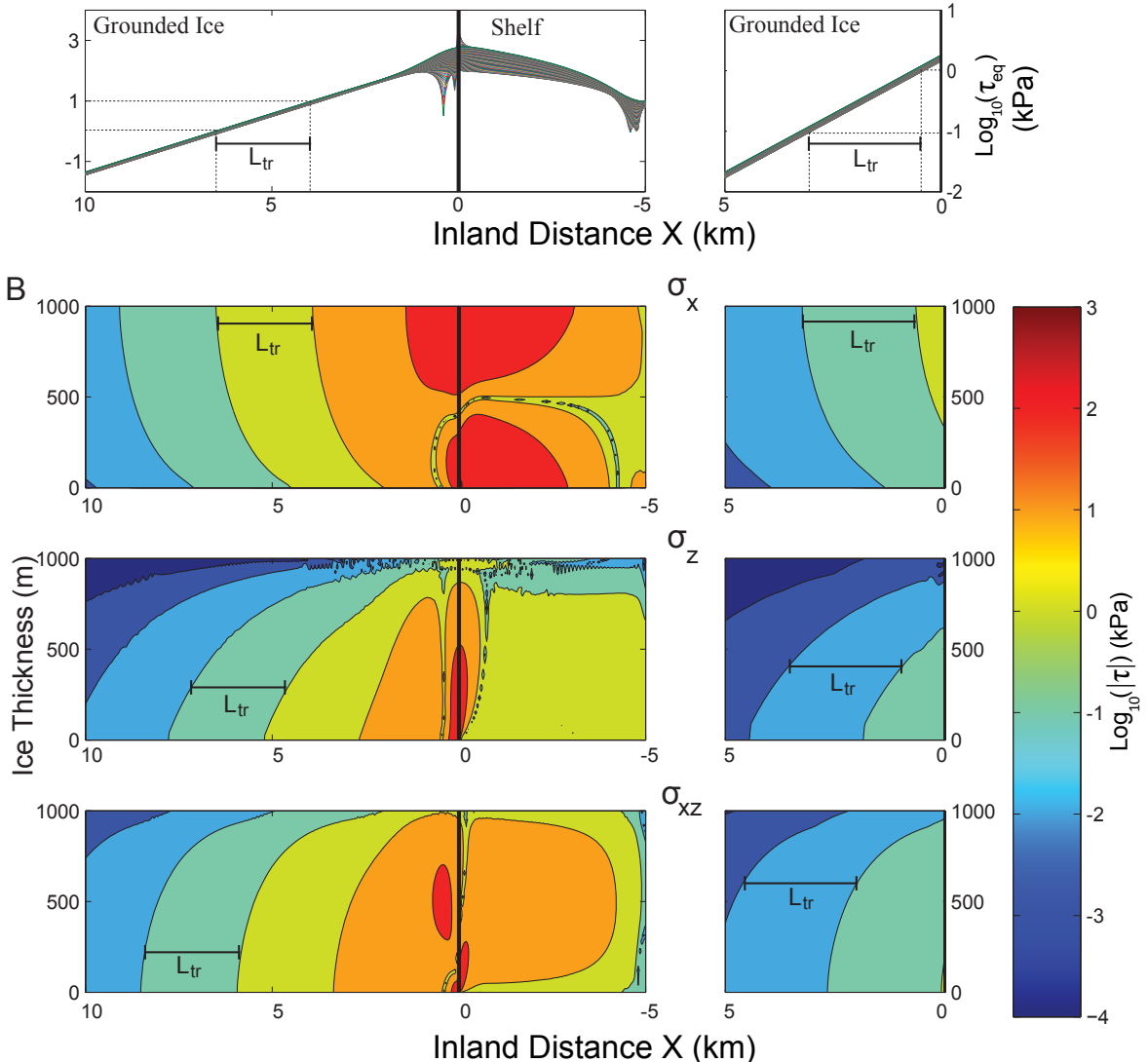

Figure 4. Stress distributions for a 2-D model with a frozen (i.e., no slip) basal condition. The panels are the same as in Fig. 3. Stress at the grounding line is higher in the model with an ice shelf than without a shelf, but $L_{\mathrm{tr}}$ is the same between the two model setups.

In the model with a free-sliding bed and no ice shelf (Fig. 3, right column), the axial stresses do not decay with distance from the grounding line. Flexural stresses, only present in the model with an ice shelf (Fig. 3, left column), follow the expected functional form of a sinusoid multiplied by an exponential function (e.g., Turcotte and Schubert, 2002). The first wavelength of this sinusoid can be seen in Fig. 3a, with a zero crossing approximately $2 \mathrm{~km}$ inland (i.e., left) of the grounding line. After moving approximately $5 \mathrm{~km}$ inland of the grounding line, the two model ice streams attain approximately the same (constant) stress value independent of the presence or lack of an ice shelf. For the model with a frozen bed (Fig. 4), flexural and axial stresses decay exponentially with distance inland of the grounding line with similar values of $L_{\mathrm{tr}}$.

These 2-D models provide an opportunity to investigate the role that the ice shelf plays in the transmission of tidal stress inland of the grounding line. As the flexural stresses induced by an ice shelf decay rapidly with distance inland of the grounding line without affecting the decay of axial stress, we choose to neglect the ice shelf in the 3-D models. See
Appendix A for a full discussion of the ice shelf's influence on these model results.

\subsection{Three-dimensional results}

We now consider the decay of stress in a uniform 3-D model, using a $1 \mathrm{~km}$ thick and $10 \mathrm{~km}$ wide ice stream as a representative model. Although they are not discussed here in detail, we also considered models with widths of $14,20,30,40$, and $50 \mathrm{~km}$ thicknesses between 1 and $3 \mathrm{~km}$, and elastic moduli 1 order of magnitude larger and smaller than the nominal 9.33 GPa value (see Table 5 for a summary of 3-D model results).

Figure 5 shows values of $\tau_{\text {eq }}$ taken along horizontal profiles at $10 \mathrm{~m}$ depth intervals (varying the $z$ coordinate) and a transverse spacing of $1 \mathrm{~km}$ (varying the $y$ coordinate). We find that stress decays exponentially over approximately the same distance independent of the $y$ or $z$ coordinates chosen. Thus, the model can be described using a single value of $L_{\mathrm{tr}}$ as shown. As our uniform 3-D model includes lateral restraint due to non-streaming ice, the stress decay behavior 
Table 3. Length scales for the transmission of tidal stress $\left(L_{\mathrm{tr}}\right)$ for the 2-D models shown in Figs. 3 and 4 . See text for description of how the parameters are estimated. All but one of the cases have low standard deviations. In the cases marked with an asterisk, the standard deviation is large since the value of $\sigma_{x}$ falls to zero near the (vertical) center of the ice stream, causing $L_{\text {tr }}$ to vary significantly near these locations. Near the top and bottom of the ice stream, the values of $L_{\mathrm{tr}}$ for $\sigma_{x}$ are consistent with the values for the other components of stress.

\begin{tabular}{|c|c|c|c|c|c|c|c|}
\hline \multicolumn{4}{|c|}{ Fixed base } & \multicolumn{4}{|c|}{ Sliding base } \\
\hline Condition & Component & $L_{\mathrm{tr}}(\mathrm{km})$ & St dev. & Condition & Component & $L_{\mathrm{tr}}(\mathrm{km})$ & St. dev. \\
\hline \multirow[t]{3}{*}{ Shelf } & $\mathrm{X}$ & 2.586 & 0.004 & Shelf & $X$ & 1.304 & $9.049 *$ \\
\hline & $\mathrm{Y}$ & 2.619 & 0.095 & & $\mathrm{Y}$ & 1.101 & 0.013 \\
\hline & XY & 2.590 & 0.015 & & $X Y$ & 1.078 & $1.4 \mathrm{e}-5$ \\
\hline \multirow[t]{3}{*}{ Axial only } & $\mathrm{X}$ & 2.517 & 0.023 & Axial only & $X$ & $\infty$ & N/A \\
\hline & $\mathrm{Y}$ & 2.618 & 0.068 & & $\mathrm{Y}$ & N/A & N/A \\
\hline & XY & 2.616 & 0.018 & & $X Y$ & N/A & N/A \\
\hline
\end{tabular}

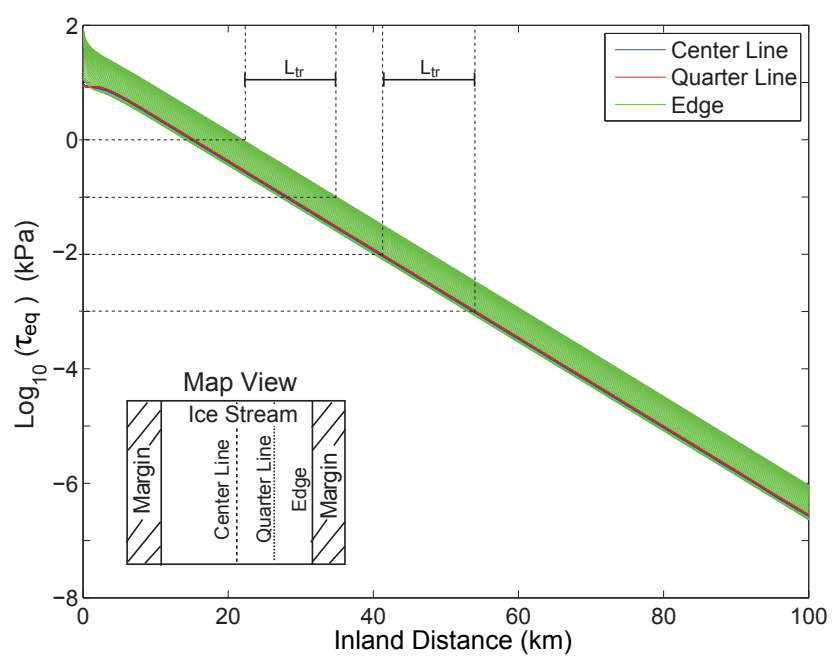

Figure 5. Stacked equivalent stress $\left(\tau_{\mathrm{eq}}\right)$ profiles for three different locations in a 3-D homogeneous elastic model $10 \mathrm{~km}$ wide and a $1 \mathrm{~km}$ thick. Inset shows locations of the three profiles in map view. For each location, 101 lines are stacked, taken at $10 \mathrm{~m}$ depth intervals. For the center and quarter lines, there is little difference in stress with depth, while for the edge of the ice stream, the stress changes with depth by about an order of magnitude. However, $L_{\mathrm{tr}}$ is the same independent of lateral position (center, quarter, or edge).

of the 3-D model is unsurprisingly different from that of the 2-D models, which do not include lateral resistance.

Figure 6 shows the full stress field (i.e., all six independent stress components) taken at the base of the representative 3-D model described above. The longitudinal normal stresses $\left(\sigma_{x x}\right)$, transverse normal stresses $\left(\sigma_{y y}\right)$, and the shear due to the sidewalls $\left(\sigma_{x y}\right)$ are the largest stresses more than a few ice thicknesses inland of the forced edge. The vertical normal stress $\left(\sigma_{z z}\right)$ at the bed is also nonzero inland of the forced edge but is at least an order of magnitude smaller than the aforementioned stresses. The vertical shear stress components $\left(\sigma_{x z}\right.$ and $\left.\sigma_{y z}\right)$ are direct consequences of stress concentration at the transition from sliding to frozen basal boundary
Table 4. $L_{\mathrm{tr}}$ for 2-D models with a zero-displacement basal condition. Note that $L_{\mathrm{tr}}$ values are linear with thickness and independent of Young's modulus.

\begin{tabular}{lrc}
\hline $\begin{array}{l}\text { Thickness } \\
(\mathrm{km})\end{array}$ & $\begin{array}{r}\text { Young's } \\
\text { modulus } \\
(\mathrm{GPa})\end{array}$ & $\begin{array}{c}L_{\mathrm{tr}} \\
(\mathrm{km})\end{array}$ \\
\hline 1 & 0.933 & 2.53 \\
2 & 0.933 & 5.07 \\
3 & 0.933 & 7.60 \\
1 & 9.33 & 2.53 \\
2 & 9.33 & 5.07 \\
3 & 9.33 & 7.60 \\
1 & 93.3 & 2.53 \\
2 & 93.3 & 5.07 \\
3 & 93.3 & 7.60 \\
\hline
\end{tabular}

conditions, and they decay rapidly with distance from both the lateral margins and the grounding line.

\subsection{Geometric factors influencing the transmission of tidal stresses}

Our 2-D and 3-D results show that tidal stresses decay exponentially with distance inland of the grounding line when basal and/or lateral resistances act on our model ice stream. We use $L_{\text {tr }}$ as a direct measure of the distance that a tidal load influences the motion of an ice stream. Note that we use a single value of $L_{\mathrm{tr}}$ estimated from $\tau_{\mathrm{eq}}$ to compare stress transmission between models and that this value of $L_{\text {tr }}$ matches the largest $L_{\text {tr }}$ calculated from the individual stress components (see Table 3). To determine the influence that the choice of geometry and elastic moduli play in controlling $L_{\mathrm{tr}}$, we explore homogeneous elasticity over a range of these parameters as tabulated in Table 4 for the 2-D models and Table 5 for the 3-D models.

In our 2-D and 3-D models, stresses vary proportionally to the magnitude of the applied stress, while displacements 


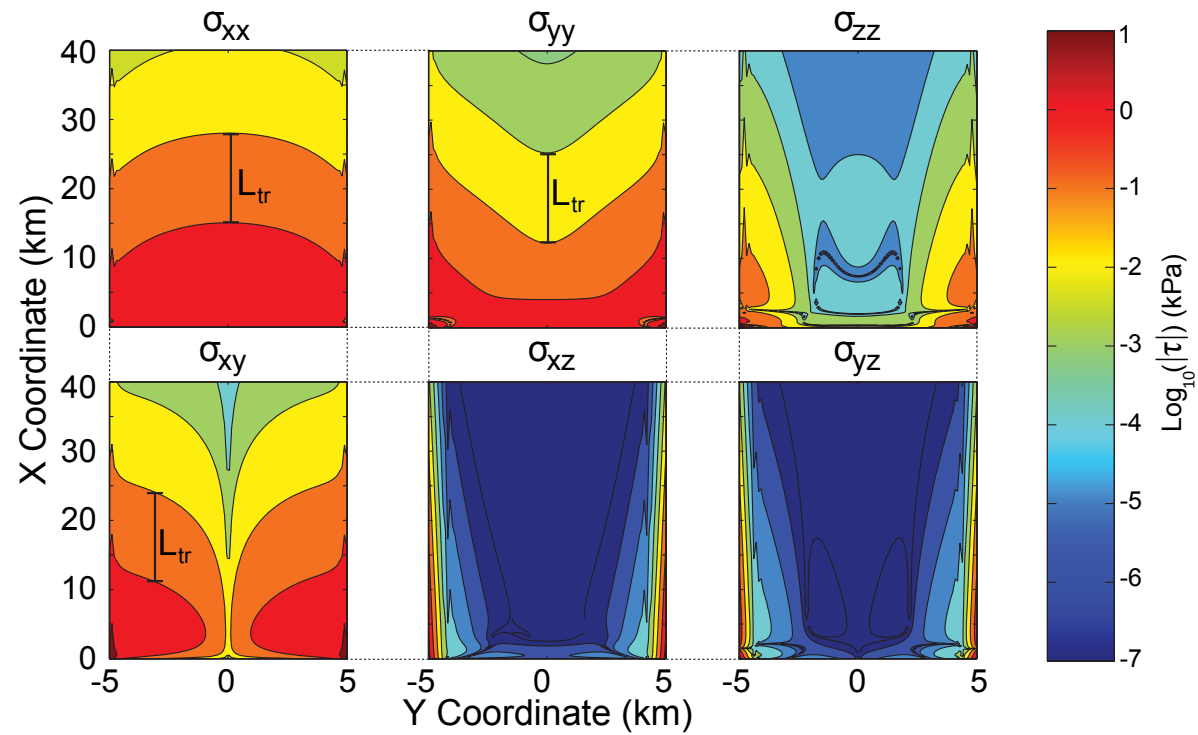

Figure 6. Representative distribution of the six unique stress components along the base of a 3-D model with homogeneous elasticity. The streaming portion of the model has a width of $10 \mathrm{~km}$ and a thickness of $1 \mathrm{~km} . L_{\mathrm{tr}}$ is drawn for the $\sigma_{x x}, \sigma_{y y}$, and $\sigma_{x y}$ stress components.

Table 5. $L_{\mathrm{tr}}$ for 3-D models with uniform Young's moduli. Like the 2-D models, $L_{\mathrm{tr}}$ is effectively independent of Young's modulus, but increases with increasing thickness and width of the ice stream. The model indicated with an asterisk is representative of Rutford Ice Stream.

\begin{tabular}{lclll}
\hline $\begin{array}{l}\text { Thickness } \\
(\mathrm{km})\end{array}$ & $\begin{array}{c}\text { Width } \\
(\mathrm{km})\end{array}$ & $\begin{array}{l}\text { Young's } \\
\text { modulus } \\
(\mathrm{GPa})\end{array}$ & $\begin{array}{l}L_{\mathrm{tr}} \\
(\mathrm{km})\end{array}$ & $\begin{array}{c}L_{\mathrm{tr}} / \\
\text { width }\end{array}$ \\
\hline 1 & 10 & 0.933 & 12.2 & 1.22 \\
1 & 10 & 9.33 & 12.7 & 1.27 \\
1 & 10 & 93.3 & 12.7 & 1.27 \\
2 & 10 & 9.33 & 13.6 & 1.36 \\
3 & 10 & 9.33 & 15.0 & 1.50 \\
1 & 14 & 9.33 & 17.5 & 1.25 \\
2 & 14 & 9.33 & 18.4 & 1.31 \\
3 & 14 & 9.33 & 19.6 & 1.40 \\
1 & 20 & 9.33 & 24.6 & 1.23 \\
2 & 20 & 9.33 & 25.6 & 1.28 \\
3 & 20 & 9.33 & 26.7 & 1.34 \\
2 & 30 & 9.33 & $38.2 *$ & 1.27 \\
2 & 40 & 9.33 & 52.2 & 1.31 \\
2 & 50 & 9.33 & 69.1 & 1.38 \\
\hline
\end{tabular}

vary proportionally to the applied stress and inversely to the Young's modulus. Such results are expected from linear elasticity. However, neither of these parameters has a pronounced effect on the decay of an applied stress as shown by the nearly constant $L_{\text {tr }}$ between models with the same geometry.

Modifying the geometry of the model affects the value of the stresses, displacements, and $L_{\text {tr }}$ in a nonlinear fashion. For the 2-D models with a frozen bed, $L_{\mathrm{tr}}$ varies linearly with thickness. For the 2-D models with a free-sliding bed, $L_{\text {tr }}$ is infinite, independent of the ice thickness. For the 3-D models, $L_{\text {tr }}$ increases with increasing thickness and width, but not in a strictly linear fashion for either.

Given these geometric dependencies, we find that the following empirical functional forms describe the relationship between the stresses, displacements, and model parameters. For the 2-D model with a frozen bed, we use

$\sigma(x, z)=\sigma_{\mathrm{GL}}(h, z) \times \Delta \bar{h} \times 10^{-x \frac{\bar{h}}{L_{\mathrm{tr}}}}$
$u(x, z)=u_{\mathrm{GL}}(h, z) \times \frac{\Delta \bar{h}}{\bar{E}} \times 10^{-x \frac{\bar{h}}{L_{\mathrm{tr}}}}$

where $\sigma_{\mathrm{GL}}$ and $u_{\mathrm{GL}}$ are, respectively, the stress and displacement at the grounding line for a $1 \mathrm{~km}$ thick model using the nominal value of $9.8 \mathrm{GPa}$ for $E$ with a $1 \mathrm{~m}$ ocean tide; $\bar{E}$ is the non-dimensionalized Young's modulus with respect to the canonical value; $\bar{h}$ is the non-dimensionalized model thickness with respect to a $1 \mathrm{~km}$ reference value; and $\Delta \bar{h}$ is the non-dimensionalized tidal height with respect to a $1 \mathrm{~m}$ tide. For the 3-D models, we find the functional forms

$\sigma(x, y, z)=\sigma_{\mathrm{GL}}(y, z, h, w) \times \Delta \bar{h} \times 10^{\frac{-x}{L_{\mathrm{tr}}(h, w)}}$
$u(x, y, z)=u_{\mathrm{GL}}(y, z, h, w) \times \frac{\Delta \bar{h}}{\bar{E}} \times 10^{\frac{-x}{L_{\mathrm{tr}}(h, w)}}$.

The implications of these results are that the stress distributions depend only on tidal loading and geometry. As long as we assume homogenous elasticity, the stress state is independent of the elastic properties in the model, although this is not true for models with spatially variable elastic moduli, as discussed in the next section. $L_{\mathrm{tr}}$ depends only on the model's geometry. 
Models with widths between 10 and $50 \mathrm{~km}$, summarized in Table 5, demonstrate that $L_{\text {tr }}$ is roughly 1.2 to 1.5 times the ice stream width. Additionally, $L_{\mathrm{tr}}$ increases only slightly as ice thickness is increased from 1 to $3 \mathrm{~km}$. Thus, tidal stresses at a distance equivalent to two ice stream widths $(2 w)$ inland of the grounding line should be considerably reduced.

\subsection{Comparison to Rutford Ice Stream}

We now compare the observed decay of GPS surface displacements from Rutford Ice Stream to the decay of tidal stresses in a model ice stream that is $30 \mathrm{~km}$ wide (a geometry approximating Rutford Ice Stream). Recall that for linear elasticity an exponential decay of stress will necessarily predict an exponential decay of displacement with the same decay rate, so such a comparison is permissible for linear elastic models. The estimated $L_{\mathrm{tr}}$ for geometries approximating Rutford Ice Stream is $38.2 \mathrm{~km}$ (flagged model in Table 5). We note that our geometrically simple model assumes that both margins are equally strong; in actuality, Rutford Ice Stream has one ice-ice interface and one ice-rock interface. However, based on the velocity profile for Rutford Ice Stream (Joughin et al., 2006), the difference between Rutford's lateral margins does not appear to strongly control the behavior of the ice stream as a whole, allowing us to make a first-order approximation of Rutford as having strong, nonfrictional boundary conditions on both lateral margins.

Figure $7 \mathrm{~b}$ demonstrates that the modeled decay is too severe to match the maximum observed displacement at GPS stations on Rutford Ice Stream inland of the grounding line (GPS data reported by Gudmundsson, 2007, and provided by H. Gudmundsson). This result suggests that resistance from lateral margins of the ice stream, at least for a channelized one like Rutford Ice Stream, are sufficiently large to limit the inland transmission of a tidal load, even in the case of frictionless sliding. In the next two sections, we consider potential mechanisms for decoupling the ice stream from its lateral margins.

\section{Weakening in the ice stream margins}

In the previous section, we demonstrated that the lateral resistance from the shear margins of a channelized ice stream dampens the inland transmission of tidal stresses significantly. However, as shear margins are locations of enhanced viscous strain (e.g., Dahl-Jensen and Gundestrup, 1987; Echelmeyer and Zhongxiang, 1987; Paterson, 1991; Echelmeyer et al., 1994) and crevassing (e.g., Cuffey and Paterson, 2010), it is conceivable that ice stream margins are elastically more compliant than the central portion of the ice stream. We now investigate the potential impact that such marginal compliance has on the inland transmission of tidal stress and find that substantial damage in the marginal ice is
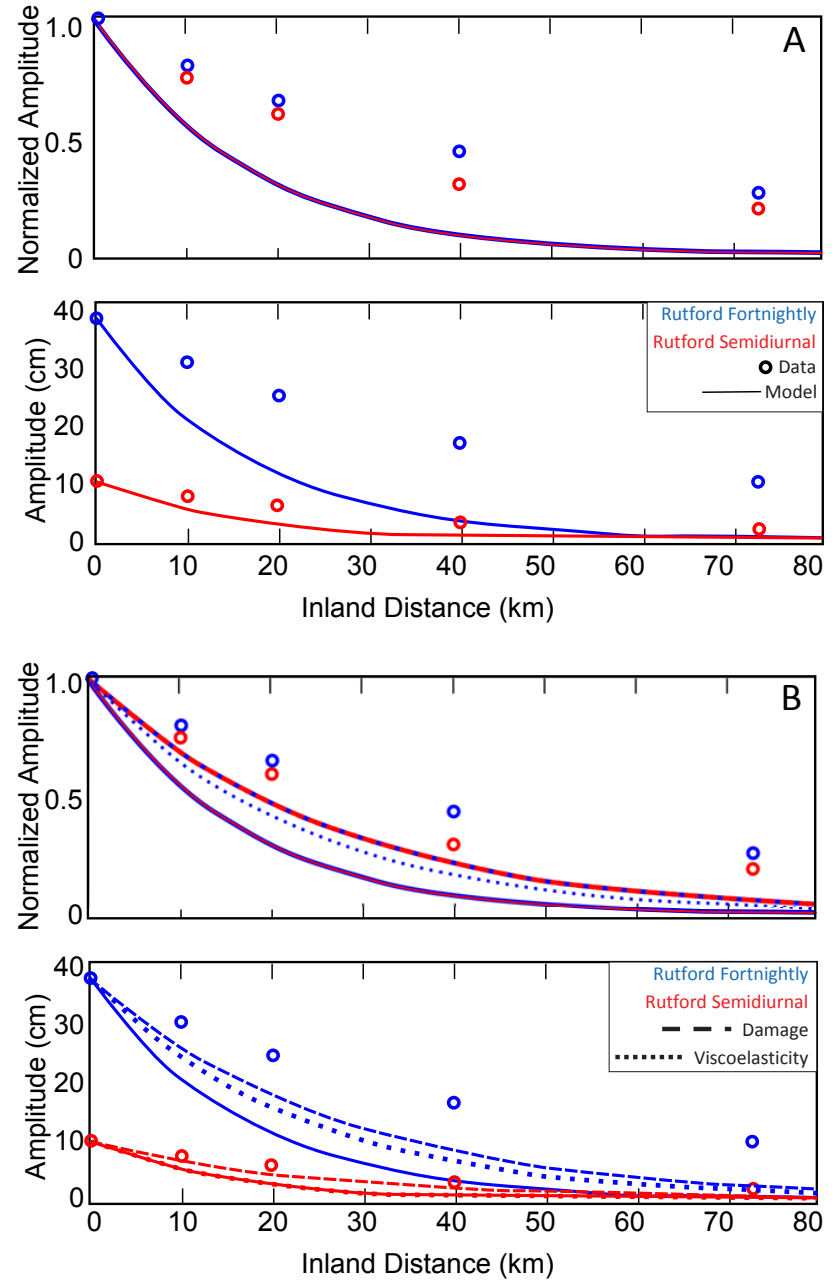

Figure 7. Comparison of observed GPS tidal displacement amplitudes to modeled displacement amplitudes. Circles show data taken from Rutford Ice Stream (data courtesy of H. Gudmundsson). The error on the approximated tidal displacement amplitudes is two centimeters (roughly the size of the symbol). Parameters for the models approximating Rutford Ice Stream as are indicated in Table 5. The upper panel shows the normalized tidal amplitudes, while the lower panel shows the true amplitude values. (a) shows the distance dependence of the equivalent stress calculated from linear, homogeneous elastic model results, while (b) shows the equivalent stress calculated using models accounting for elastic damage in the shear margins (dashed) and temperature-dependent viscoelasticity (dotted).

necessary to decouple the ice streams enough that the models reproduce observations of tidally modulated ice motion.

\subsection{Methodology}

Theoretically, the damage is expected to reduce the effective Young's modulus (e.g., Walsh, 1965). We parameterize the influence of cracks and crevasses using linear elastic continuum damage mechanics. This approach modifies the elastic 


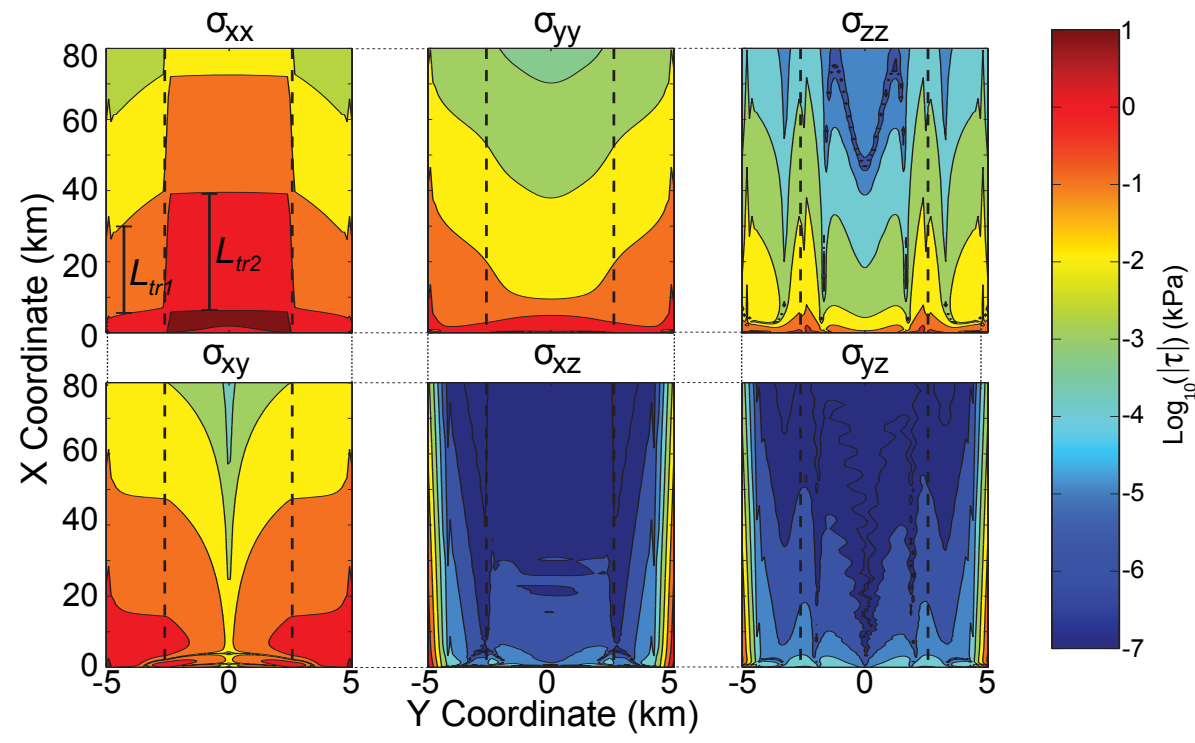

Figure 8. Representative distribution of stress for a model with the same geometry as Fig. 6, but with ice margins that are $25 \%$ of the ice stream width. These margins are a factor of 10 more compliant than in the center of the ice stream.

constitutive equation by multiplying the Young's modulus with a damage term (see Murakami, 2012, and references therein):

$\varepsilon=\frac{\sigma}{E(1-D)}$.

The damage parameter $D$ can take a value from 0 (no damage) to 1 (complete plastic failure) and has the physical interpretation as the fraction of area that can no longer support a load due to the opening of void space in the damaged body. For reference, Borstad et al. (2012) find the threshold for calving in an ice shelf to be $D=0.6 \pm 0.1$, which is comparable to the value of damage calculated from viscous flow enhancement factors for an Antarctic ice stream (e.g., Echelmeyer et al., 1994) using a viscous implementation of damage (see Eq. 7 below).

We modify our 3-D model to have a laterally variable Young's modulus with two different patterns of variability (see inset in Fig. 2b): one with a step function drop in Young's modulus at certain predetermined ice margin widths ("discrete margins") and the other with a linear reduction of the Young's modulus from the middle to the edges of the ice stream ("continuous margins"). For both patterns, the elasticity profile is symmetric across the centerline of the ice stream, such that the natural transverse length is the ice stream half-width. For the discrete margin pattern, we evaluate a range of margin widths at $10 \%$ intervals between 10 and $90 \%$ of the ice stream half-width. The marginal ice in these models has a reduction in Young's modulus by a factor of 10 . For the continuous margins model, we evaluate models with the Young's modulus of the marginal ice reduced by factors of 10,100 , and 1000 .

\subsection{Results}

Figure 8 shows a representative distribution of the six stress components for a discrete margins model with weakened margins half of the ice stream half-width. The longitudinal normal stress $\left(\sigma_{x x}\right)$ is concentrated in the stronger ice at the center of the model, while the transverse normal $\left(\sigma_{y y}\right)$ and the horizontal shear $\left(\sigma_{x y}\right)$ stresses are concentrated in the weaker marginal ice. Comparing these stresses to Fig. 6 and noting the differing longitudinal scales, it is clear that $L_{\text {tr }}$ is larger in the model with compliant margins than in the homogenous elastic model. Additionally, as shown for the longitudinal normal stress $\left(\sigma_{x x}\right), L_{\text {tr }}$ is no longer constant throughout the model, as was the case for the homogeneous model. For this manuscript, we use a width-averaged value of $L_{\text {tr }}$ for comparison between different models with compliant margins.

Figure 9 shows the relative change in $L_{\text {tr }}$ in models with marginal weakening compared to a homogeneous elastic model with the same geometry. By interpolating between the results of our discrete margins models, we characterize $L_{\mathrm{tr}}$ as a function of the ratio of marginal width to ice stream width $(\hat{x})$. Similarly, by interpolating between the results of our continuous margins models, we characterize $L_{\text {tr }}$ as a function of the severity of marginal weakening, described by the ratio of the Young's modulus of the marginal ice to that of the central ice $(\hat{E})$. Figure 9 demonstrates that the maximum increase to $L_{\text {tr }}$ occurs when each shear margin is about $50 \%$ of the ice stream half-width and that $L_{\mathrm{tr}}$ increases as lateral margins become more compliant relative to the central ice stream. 


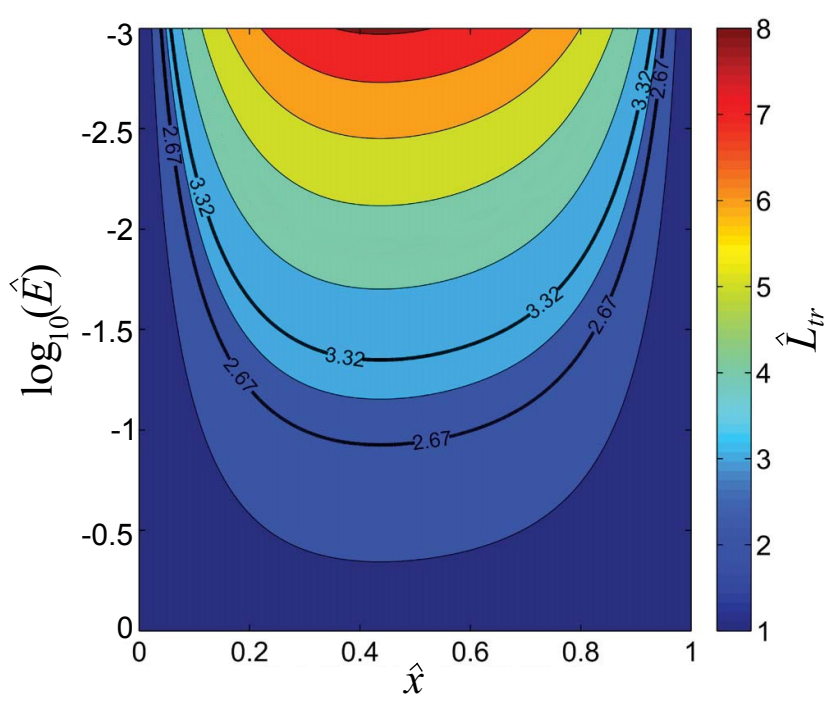

Figure 9. Dependence of $L_{\text {tr }}$ on the value of Young's modulus of the margins $(\hat{E})$ and the width of the margin $(\hat{x})$ for a discrete margin model all taken relative to the homogeneous elastic model. Colored contours show the relative increase in $L_{\mathrm{tr}}$ compared to a homogeneous linear elastic model $(\hat{E}=1)$. The two bold contours correspond to the conditions necessary to explain the observations of the Rutford fortnightly tidal signal (2.67) and the Rutford semidiurnal tidal signal (3.32).

\subsection{Viability of lateral weakening as a decoupling mechanism}

Figure 9 also shows two contours that correspond to increases in $L_{\text {tr }}$ necessary to reproduce observations of the semidiurnal and fortnightly tidal displacements at Rutford Ice Stream (a relative value of $L_{\text {tr }}$ of 3.32 and 2.67, respectively). As the shear margins for Rutford Ice Stream are on the order of $10 \%$ half-width (e.g., Joughin et al., 2006), we find the minimum values of $\hat{E}$ needed to reproduce the observed values of $L_{\text {tr }}$ to be $1995\left(10^{3.3}\right)$ and $630\left(10^{2.8}\right)$, respectively. These values of $\hat{E}$ correspond to linear damage parameters of $D=0.9995$ and $D=0.998$ (Eq. 6).

To add some physical meaning to these estimates of $D$, we compare these modeled values to the critical damage threshold values of $D$, commonly named $D_{\mathrm{C}}$, found in the literature. $D_{\mathrm{C}}$ is the linear damage value at which a material becomes sufficiently fractured to stop behaving as a single continuous body. From laboratory experiments, $D_{\mathrm{C}}$ has been estimated to be $0.45-0.56$ for ice (Pralong and Funk, 2005; Duddu and Waisman, 2012). From inverse modeling of the Larsen B Ice Shelf collapse using a viscous model with linear continuum damage, Borstad et al. (2012) found $D_{\mathrm{C}}$ for calving to be $0.6 \pm 0.1$. To compare $D_{\mathrm{C}}$ with our model results, we must remember that the above values for $D_{\mathrm{C}}$ are for nonlinear viscous flow, such that the "enhancement" value is governed by
$E n=(1-D)^{-n}$.

Thus, the corresponding enhancements for the literature values of $D_{\mathrm{C}}$ are between about 6 (for $D_{\mathrm{C}}=0.45$ ) and 37 (for $D_{\mathrm{C}}=0.7$ ) using the canonical power law exponent for Glen flow of $n=3$. Even the smallest necessary enhancement for our models has a value of $467.7\left(10^{2.67}\right.$ for the fortnightly tide on Rutford Ice Stream), suggesting that the damage required to create sufficient marginal compliance to match observations is too high to be physically reasonable. Thus, we find that incorporating damage in an ice stream's shear margins is insufficient to bring model-predicted estimates of $L_{\text {tr }}$ into agreement with those found observationally from GPS stations on Rutford Ice Stream.

\section{Viscoelasticity}

We now investigate the potential for viscoelasticity to decouple the ice stream from its lateral margins and thus increase the inland transmission of a tidal load relative to a homogeneous elastic model. As an ice stream's margins are the location of large shear stresses, an ice stream with stressdependent viscoelasticity should have reduced effective viscosity in these lateral margins. The net result would be that deformation is concentrated near the lateral margins, decoupling of the ice stream from its margins and allowing for a longer inland transmission of a tidal stress.

\subsection{Methodology}

To incorporate viscoelasticity into our ice stream models, we change our rheology from the linear elastic model used previously (Eq. 2) to a Glen-style viscoelastic model:

$\dot{\varepsilon}=\frac{\dot{\sigma}}{E}+A \sigma^{n}$,

where we take the nominal value $n=3$. For the viscosity coefficient $A$, we present two models. The first is a homogenous viscous model, using the canonical value of $A$ equal to the $0^{\circ} \mathrm{C}$ value (e.g., Cuffey and Paterson, 2010). The second model uses the Arrhenius relationship for temperature-dependent viscosity from Cuffey and Paterson (2010, Eq. 3.35), along with a temperature profile chosen to match the empirical relation calculated from the Whillans Ice Plain in Engelhardt and Kamb (1993). The elastic moduli are the same as in the homogenous elastic models.

Incorporating both viscoelasticity and nonlinearity into the constitutive law for ice introduces many additional modeling concerns in order to correctly describe the link between ocean tides and ice stream motion. As we cannot use superposition in a model with stress-dependent viscosity, we apply the down-glacier (i.e., deviatoric) component of the gravitational body force to the model. In the finiteelement formulation, we apply the horizontal component of 
gravity ( $g_{\text {horiz }}=g \sin \alpha$, where $\alpha$ is the surface slope) as a time-constant acceleration acting on the entire ice body. We choose to apply only the down-glacier component of gravity out of convenience, as using the full gravitational body force would require us to apply a pre-stress to the model to cancel out the vertical component of the full gravitational body force; otherwise the model would compress when gravity is "turned on" at time 0 .

For models using a viscoelastic rheology for ice, we apply a sinusoidally varying tide of magnitude $\rho g \Delta h$ at a range of tidal periods. See Appendix $C$ for a discussion of the impact this tidal loading condition has on a viscoelastic model. We use three main tidal constituents (i.e., the semidiurnal, diurnal, and fortnightly tides) in our forcing functions for the viscoelastic models. For simplicity, we approximate the tidal periods of these tidal constituents as $12 \mathrm{~h}, 24 \mathrm{~h}$, and 14 days, respectively. Of course, the three tidal constituents cannot strictly be separated due to the nonlinearity of the viscous deformation, and research by Gudmundsson (2006, 2007, 2011) and Rosier et al. (2014) suggests that fortnightly variability in ice stream motion is a consequence of the nonlinear interaction of the semidiurnal ocean tides acting on basal friction beneath the ice stream. Given that our models neglect basal friction and thus cannot reproduce an apparent fortnightly tidal signal due to basal friction, we opt instead to focus our modeling efforts on identifying the relationship (if any) between forcing frequency and $L_{\mathrm{tr}}$. To this end, we model the individual tidal frequencies rather than a more accurate combined tidal loading function. To ensure that the model is appropriately "spun-up" (e.g., Hetland and Hager, 2005), we only present results that have been run long enough such that the detrended, oscillatory motion is consistent over consecutive tidal cycles.

A final consideration is the strong temperature dependence of the ice viscosity (e.g., Weertman, 1983; Hooke and Hanson, 1986; Paterson, 1994; Cuffey and Paterson, 2010). The temperature dependence of the viscosity coefficient, from Cuffey and Paterson (2010), is

$$
A=2.4 \times 10^{-24} \exp \left(\frac{-6 \times 10^{4}}{8.314} \times\left[\frac{1}{T}-\frac{1}{263}\right]\right) \mathrm{Pa}^{-3} \mathrm{~s}^{-1}
$$

for $T<263 \mathrm{~K}$

$A=3.5 \times 10^{-25} \exp \left(\frac{-1.39 \times 10^{5}}{8.314} \times\left[\frac{1}{T}-\frac{1}{263}\right]\right) \mathrm{Pa}^{-3} \mathrm{~s}^{-1}$

for $T>263 \mathrm{~K}$,

where $T$ is measured in kelvin (K). Antarctic ice streams have been observed to have a strong temperature gradient from the base to the surface (e.g., Engelhardt et al., 1990; Engelhardt and Kamb, 1993, 1998; Engelhardt 2004a, b), with some ice stream beds up to $20 \mathrm{~K}$ warmer than the ice stream's surface. We adopt an empirical fit of temperature data from Whillans Ice Stream as the temperature profile in all models. The temperature gradient of such a temperature profile is defined by Engelhardt and Kamb (1993) as

$\frac{\mathrm{d} T}{\mathrm{~d} z}=q_{\mathrm{b}} e^{-y^{2}}+\frac{\lambda a u l}{\kappa} e^{-y^{2}} \int_{0}^{y} e^{-t^{2}} \mathrm{~d} t$,

where $y=z / l, l=2 \kappa H / a, q_{\mathrm{b}}$ is the basal temperature gradient, $a$ is the accumulation rate, $u$ is the ice stream horizontal velocity, $\kappa$ is the thermal diffusivity, $H$ is the ice stream thickness, and $\lambda$ is the temperature gradient in air. All values of these parameters, except model geometries, are taken from Engelhardt and Kamb (1993). In solving for the temperature profile, we set the basal temperature equal to the pressure melting point of ice, $-0.7^{\circ} \mathrm{C}$.

\subsection{Results}

Our primary interest in modeling stress-dependent viscoelasticity is to determine whether this rheology results in substantial decoupling of the ice stream from its lateral margins. Based on our estimates of tidal stress decay at Rutford Ice Stream, viscoelasticity would need to increase our model's $L_{\text {tr }}$ by a factor of between 2 and 4 to match the field observations of Gudmundsson $(2007,2008,2011)$. Due to the sinusoidal tidal loading function, we fit stress profiles along the modeled ice stream's length with

$\sigma_{x x}=A(x, y, z) \sin (\omega t+\phi)$,

where $A$ is the stress amplitude as a function of $x, y$, and $z$; $\omega$ is the tidal frequency of the applied tide; and $\phi$ is the phase delay. As with our elastic models, we observe an exponential decay of tidal stress inland of the grounding line. We can use the distance dependence of $A$ to calculate $L_{\text {tr }}$ for a given model. Figure 10 shows the values of $L_{\mathrm{tr}}$, stress, and phase delay for a representative model ( $1 \mathrm{~km}$ thick and $10 \mathrm{~km}$ wide) using a semidiurnal tide.

In addition to the three tidal frequencies, we also explore different tidal loading conditions (simple vs. full; see Appendix C) and viscosities (homogeneous vs. temperaturedependent) in our models. The modeled values of $L_{\mathrm{tr}}$ for these viscoelastic models are summarized in Table 6. From this table, we see that incorporating the more realistic temperature-dependent viscosity results in an increase in $L_{\text {tr }}$ by less than $50 \%$ for all tidal frequencies.

\subsection{Viability of viscoelasticity as a decoupling mechanism}

The shear margins have a reduced effective viscosity compared to the central ice (Fig. 11). This viscosity contrast reflects the stress distribution induced by the background (gravitational) flow and does not vary notably over a tidal cycle. This result suggests that the background flow, even 

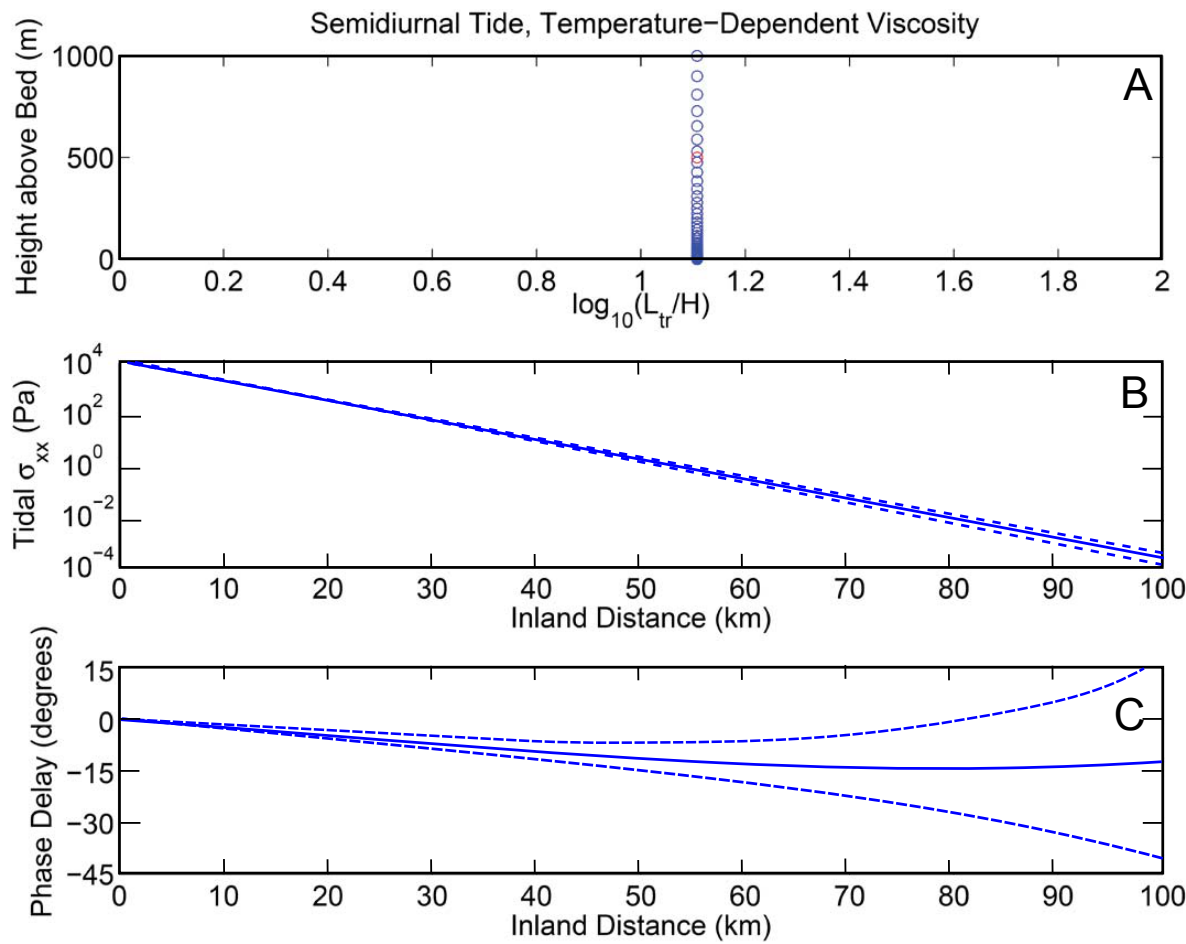

Figure 10. Model results for a temperature-dependent viscoelastic model forced by a semidiurnal tide. (a) shows the calculated values of $L_{\mathrm{tr}}$ for depth profiles of the stress with result in an average value of $L_{\mathrm{tr}}$ of $12.81 \pm 0.001 \mathrm{~km}$. (b) shows the value of the longitudinal normal stress $\left(\sigma_{y y}\right)$ as a function of horizontal coordinate. (c) shows the fitted phase shift $\varphi$ as a function of horizontal coordinate. In (b) and (c), the dashed lines correspond to the $95 \%$ confidence interval values of the fit.

Table 6. Summary of the $L_{\mathrm{tr}}$ for the viscoelastic models. Viscosity models are either homogeneous (homog.) or temperature dependent (temp.). We include homogeneous models only for completeness since we consider the temperature-dependent models to be more physically realistic. The applied force describes the nature of the tidal loading applied in the model, as is described in Appendix C.

\begin{tabular}{llll}
\hline Tide & $\begin{array}{l}\text { Applied } \\
\text { force }\end{array}$ & Viscosity & $\begin{array}{c}L_{\mathrm{tr}} \\
(\mathrm{km})\end{array}$ \\
\hline Semidiurnal & Full & Temp. & 14.4 \\
Semidiurnal & Simple & Temp. & 16.4 \\
Semidiurnal & Simple & Homog. & 33.0 \\
Diurnal & Full & Temp. & 13.1 \\
Diurnal & Simple & Temp. & 12.8 \\
Diurnal & Simple & Homog. & 29.2 \\
Fortnightly & Simple & Temp. & 17.7 \\
Fortnightly & Simple & Homog. & 44.4 \\
\hline
\end{tabular}

for low driving stresses, controls the effective viscosity in our models with stress-dependent viscosity. It is beyond the scope of this paper, but such a result suggests that the viscoelastic response of an ice stream to a tidal load can be approximated using linear viscoelasticity if the ice stream is modeled using a spatially variable effective viscosity that

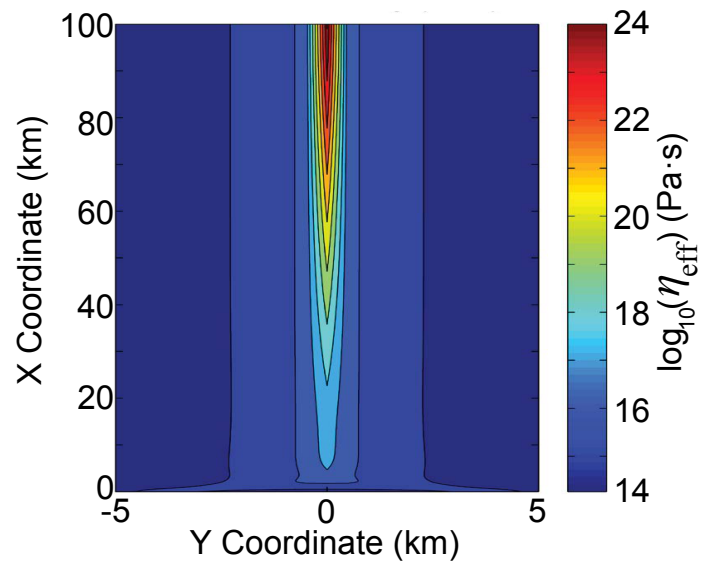

Figure 11. Effective viscosity of semidiurnal models taken at the base of the homogeneous viscosity model. The streaming domain of the ice stream is $10 \mathrm{~km}$ wide $(-5$ to $+5 \mathrm{~km})$. Note that the shear margins have substantially reduced viscosity relative to the central ice.

accounts for the background gravitational stress in the ice stream.

However, even a large contrast in viscosity between the shear margins and central ice stream fails to cause a substantial increase in $L_{\mathrm{tr}}$. While ice is expected to be less viscous in the shear margins, the marginal ice's viscosity is too large for 
substantial viscous deformation over a tidal cycle. The smallest effective viscosities in our temperature-dependent models are on the order of $10^{14} \mathrm{~Pa} \mathrm{~s}^{-1}$ in the (warmer) ice at the base of the ice stream's shear margins. This minimum viscosity is about 2 orders of magnitude larger than the linear viscosity found for laboratory ice (e.g., $10^{12} \mathrm{~Pa} \mathrm{~s}^{-1}$, from Jellinek and Brill, 1956).

Additionally, the shortest Maxwell time for the modeled ice stream is about $10^{4} \mathrm{~s}(\sim 3 \mathrm{~h})$, again in the warm ice at the base of the shear margins. As mentioned above, even here the ice stream's response is primarily elastic. Only when the model is forced with longer-period oscillations (e.g., the fortnightly tide) does adding ice viscoelasticity to the model increase $L_{\text {tr }}$ by a meaningful amount due to viscous deformation in the ice stream. However, as mentioned previously, the fortnightly tidal signal observed at Rutford Ice Stream is likely the results of nonlinear interactions between different semidiurnal tides (Gudmundsson, 2006, 2007, 2011; Rosier et al., 2014), so the calculated increase in $L_{\mathrm{tr}} \mathrm{f}$ or the fortnightly tide may not be representative of real-world conditions. Ultimately, the temperature dependence of ice viscosity and the low temperatures in the majority of the ice stream cause the ice's response to a tidal stress to be predominantly elastic, even in the shear margins.

\section{Discussion}

St. Venant's principle states that the influence of an applied concentrated load on an elastic body is negligible at great distances away from the applied load (e.g., Goodier, 1942; Timoshenko and Goodier, 1982). For instance, Goodier (1942) demonstrates that an axially forced block, when restrained from below, has a stress field that is only important close to the forced edge. Additionally, Goodier establishes the same conclusion when the block is fixed from both above and below. These two cases are identical to our 2-D model with a frozen base and a 2-D version (in map view) of our 3-D ice stream model, respectively. Timoshenko and Goodier (1982) provide an explicit form of the stress solution for similar, albeit not identical, models. In their article 24, they describe the expectation of exponential decay of stress with distance away from a point load applied to the opposite edges of a beam. Thus, it should not be a surprise that we find an exponential decay of stresses in these ice stream models.

Previous models for tidal influences on ice stream motion also found an exponential decay of stress with distance inland of the grounding line (e.g., Anandakrishnan and Alley, 1997; Sergienko et al., 2009). Our 2-D model results represent extremes of Anandakrishnan and Alley's (1997) model. The frozen-bed model corresponds to Anandakrishnan and Alley's model with either a zero-thickness viscous layer or an infinitely viscous $(\eta \approx \infty)$ layer. The slidingbed model corresponds to Anandakrishnan and Alley's model with an infinitely weak $(\eta \approx 0)$ viscous layer. As the two-layer models of Anandakrishnan and Alley have the additional free parameter of till viscosity, Anandakrishnan and Alley's (1997) models can constrain till viscosity using $L_{\text {tr }}$ or constrain $L_{\text {tr }}$ using till viscosity, but not both simultaneously. Additionally, the lack of lateral restraint in the model allows for the physically unrealistic case of infinite stress transmission. The same issue is present in the flowline models discussed in Sect. 1.2. Our model results suggest that the assumption of negligible lateral resistance is not reasonable for channelized ice streams.

Of the published models considered earlier, Sergienko et al. (2009) is the only study to explicitly account for lateral resistances. Removing the basal drag condition from the model of Sergienko et al. (2009) results in a 1-D approximation of our 3-D models. However, the lack of a clear length scale for the elastic springs in the model of Sergienko et al. (2009) prevents us from directly applying this model to constrain $L_{\text {tr }}$. As our finite-element modeling shows, the presence of both non-sliding lateral margins and a frozenbed basal boundary condition results in exponential decay of a tidal load with distance inland of the grounding line. Thus over the stick-slip cycle in Sergienko et al. (2009), we expect that the stress transmission would cycle between a thicknesscontrolled value when stuck and a width-controlled value when slipping.

In our 3-D models, ice stream width is the primary geometric control on $L_{\mathrm{tr}}$. In comparison, ice stream thickness only has a minor effect on $L_{\mathrm{tr}}$, causing a 5-10\% change in $L_{\text {tr }}$ per added kilometer of ice thickness. Extending these results, models with a realistic geometry will only vary substantially from the equivalent box model approximation if the real ice stream's width changes dramatically along the flow direction. The width of Rutford Ice Stream does not change significantly through the region with CGPS observations.

We have also shown that introducing variability in the elastic moduli can have a pronounced effect on $L_{\mathrm{tr}}$. However, the precise change in $L_{\text {tr }}$ depends on the choice of damage parameter and the shear margin size. Generally, increasing the damage (and thus elastic compliance) in the ice stream margins increases the value of $L_{\mathrm{tr}}$. However, in order to use marginal damage to increase $L_{\mathrm{tr}}$ to a value large enough to match observations, we must choose a damage coefficient significantly higher than that proposed for calving in the ice shelf $(D \sim 0.99>0.6 \pm 0.1)$. The ice stream is almost certainly not more damaged than its calving ice shelf, as otherwise having a cohesive ice shelf would be impossible. This suggests that marginal damage alone does not sufficiently decouple the ice stream from its lateral margins.

Similarly, the viscoelastic models presented here demonstrate that the reduction in marginal viscosity due to flowinduced shear is insufficient to dramatically increase $L_{\text {tr }}$ through the ice stream. While $L_{\text {tr }}$ increases slightly by using a temperature-dependent viscosity instead of homogeneous elasticity, this increase in $L_{\mathrm{tr}}$ is too small to rectify the 
model results with the observations from Rutford Ice Stream. For comparison, the change in $L_{\text {tr }}$ from viscoelasticity is comparable to the change in $L_{\mathrm{tr}}$ due to increasing compliance in the lateral margins for physically realistic damage parameters.

\subsection{Rutford Ice Stream}

Figure $7 \mathrm{~b}$ shows that the mechanisms of extreme-butphysically-reasonable damage, viscoelasticity, and both mechanisms combined linearly cannot increase modeled values of $L_{\text {tr }}$ to match observed tidally modulated ice motion from Rutford Ice Stream. We now briefly compare our model results to other tidally modulated models of Rutford Ice Stream.

In the 2-D models of Gudmundsson (2007, 2011), the surface velocity perturbations on Rutford Ice Stream due to the ocean tides are reproduced to a good approximation when both a basal sliding law and ice viscoelasticity control the propagation of the tidal load inland of the grounding line. However, these models do not account for the exponential decay of tidal stresses inland of the grounding line caused by the ice stream's lateral margins. As stated above, we find that including the lateral margins results in a value of $L_{\mathrm{tr}}$ too small to be consistent with tidally modulated observations from Rutford Ice Stream.

While the 3-D modeling of Rosier et al. (2014) qualitatively agrees with our results, there is quantitative disagreement in how these results apply to Rutford Ice Stream. In particular, our $30 \mathrm{~km}$ wide model of Rutford Ice Stream (with geometry based on imagery presented in Joughin et al., 2006) finds that tidal stresses decay more rapidly inland of the grounding line than observed in tidally modulated GPS data (Fig. 7b). The $64 \mathrm{~km}$ wide model of Rosier et al. (2014) finds a smaller $L_{\mathrm{tr}}$ at short tidal periods and a moderately larger $L_{\mathrm{tr}}$ at long tidal periods than our model. Moreover, we find that using temperature-dependent viscosity causes our model to behave more elastically than viscously over a range of tidal periods and thus using a temperature-dependent viscosity is necessary to avoid overestimating $L_{\mathrm{tr}}$. In contrast, Rosier et al. (2014) uses a constant (relatively low) viscosity in their models.

Our results suggest that these other models of Rutford Ice Stream are overestimating the inland transmission of tidal stresses. When geometric and rheological restrictions on $L_{\text {tr }}$ are included, the implicit assumption in these and our models - that stress is transmitted through the bulk of the ice stream either elastically or viscoelastically - is shown to be inconsistent with the observations from Rutford Ice Stream.

\subsection{Other ice stream geometries}

Generally, the models presented here demonstrate that channelized ice streams - even under the favorable conditions of frictionless beds, enhanced marginal shear, and viscoelastic flow - fail to reproduce the inland extent of tidal stresses observed in nature. These models draw into question the hypothesis that the observed influence of ocean tides on ice stream motion is fundamentally an elastic process. However, we have only considered a very specific range of ice stream geometries so far: ice streams that have relatively narrow widths and strong ice-ice interfaces on the lateral margins.

At least two other Antarctic ice streams have observations of tidally modulated surface displacements (Bindschadler Ice Stream and Whillans Ice Plain). For these ice streams, the assumption of ice-ice interfaces is appropriate, but using a narrow (channelized) ice stream geometry is a poor approximation of these wide ice streams, which can have nearly equal widths and lengths. Our results show that models with increasing width still exhibit exponential decay of tidal stresses, albeit over a longer distance than narrow ice streams due to the width dependence of $L_{\text {tr }}$. However, when $L_{\text {tr }}$ is normalized by ice stream width, we see from Table 5 that $L_{\mathrm{tr}} /$ width does not seem to depend directly on the ice stream width. Thus, these results for channelized ice streams may also approximately describe the stress behavior of wider ice streams. Note that in cases where an ice stream's width is comparable to its length (e.g., Whillans Ice Plain), these results suggest that a tidal load might be transmitted over a large portion of the ice stream.

However, real ice streams are neither frozen nor frictionlessly sliding over their beds; frictional sliding is known to play a major role in determining the ice stream's total flow (e.g., Weertman, 1957, 1964; Engelhardt and Kamb, 1998; Hughes, 1998; Cuffey and Paterson, 2010). However, since we assume frictionless sliding, the values of $L_{\mathrm{tr}}$ for the 3-D models should be taken as maximum values, and thus applying a frictional sliding law would only serve to reduce $L_{\text {tr }}$. As demonstrated by Rosier et al. (2014), adding basal friction can reduce the value of $L_{\mathrm{tr}}$ substantially. However, the modeling of ice streams with a similar width and length as well as the addition of a frictional basal sliding law is beyond the scope of the present study.

\subsection{An alternative mechanism for the transmission of tidal stresses}

We conclude that a process external to the ice stream is required for ocean tidal loads to impact glacier flow far inland of the grounding line for channelized ice streams. While not explored in great detail here, our preferred hypothesis is that the ocean tides perturb the subglacial hydrologic network. Because the basal traction beneath these fast-moving ice streams must be small in order to encourage sliding and because these Antarctic ice streams are underlain by waterlogged tills (e.g., Alley et al., 1986; Smith, 1997; Engelhardt and Kamb, 1998; Tulaczyk et al., 2000; Adalgeirsdottir et al., 2008; Raymond Pralong and Gudmundsson, 2011), the fluid pressure within the subglacial till is likely sufficient to cause the till either to deform plastically or at least to weaken 


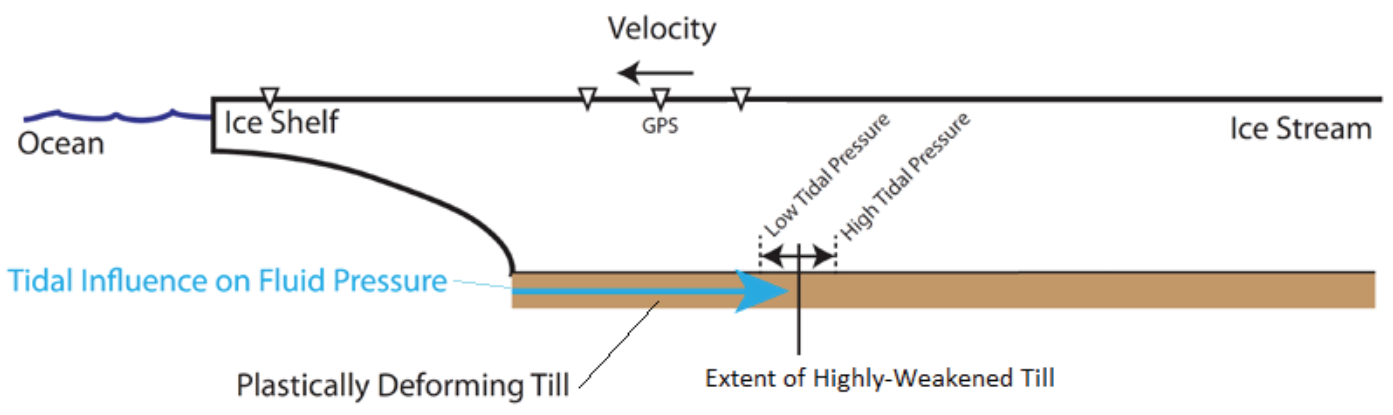

Figure 12. Schematic view of our hydrology hypothesis at neutral, high, and low tidal amplitudes, respectively. Triangles represent GPS stations on the surface of the ice stream and ice shelf. The brown layer represents subglacial till. Maximum extent of highly-weakened till is shown as a vertical line, and should vary in position with changes in the ocean tidal amplitude. When the maximum extent of highlyweakened till is farther inland, GPS stations move faster relative to a neutral position since more of the ice is streaming. Conversely, when the maximum extent of highly-weakened till is closer to the grounding line, the relative velocity of the GPS stations is lower than at a neutral tide.

in a highly nonlinear fashion. Our hypothesis is that the oscillations in ocean tidal height (i.e., hydrostatic pressure) expressed in till pore pressures can move the onset of weakened till inland and seaward over the course of a tidal cycle. As imagined in Fig. 12, when the onset of till weakening is pushed inland, the ice stream at a given point should increase velocity as a longer portion of the glacier is effectively decoupled from the bed. The opposite is true when the onset of till weakening moves oceanwards. Furthermore, as the tidal fluid pressure perturbation should decay with distance inland of the grounding line, the effect is expected to be most pronounced near the grounding line.

To derive an analytical form for this conceptual model, we start by following the 2-D flow-line approach of Gudmundsson (2007) and assume that the basal velocity of the ice stream is a nonlinear function of the basal stress:

$u_{\mathrm{b}}=C \tau_{\mathrm{b}}^{n}$,

where $C$ is a rheological coefficient, and $n \neq 1$. We then assume that $\tau_{\mathrm{b}}$ is also modulated by an effective normal stress, $\sigma_{\mathrm{e}}=\sigma_{0}-p$ (where $p$ is the local fluid pressure), through a Coulomb-type rheology for Antarctic till (e.g., Tulaczyk et al., 2000). If the connectivity of the till is high (i.e., infinitely fast), then the fluid pressure in the till is

$p(x, t)=p_{0}+\rho g h(t)$,

where $h(t)$ is the tidal height at the grounding line. If instead the connectivity is low enough that there is a resistance to flow, then one might expect the fluid pressure to instead be

$p(x, t)=p_{0}+\rho g h(t-x / U)$,

where $U$ is the flow velocity for a turbulent flow through (a channelized) subglacial till (after Manning, 1891; Tsai and Rice, 2010):

$U=\frac{1}{0.038 \times k^{1 / 6}} R^{2 / 3}\left(\frac{\mathrm{d} H}{\mathrm{~d} x}\right)^{1 / 2}$, where $k$ is the Nikuradse roughness height for the till, $R$ is the radius of the flow channel, and $H$ is the head in the flow channel. In either case, the basal stress is

$\tau_{\mathrm{b}}=f \sigma_{\mathrm{e}}=\tau_{\mathrm{b} 0}-f \rho g h(t-x / U)$,

where $f$ is the friction angle, which is typically $f \leq 0$.6. If we define the basal velocity $u_{\mathrm{b}}$ by Eq. (12), then the current model's form, with infinitely high connectivity, is exactly equivalent to the model of Gudmundsson (2007) except that Gudmundsson's constant $K$ is replaced with $f$, despite Gudmundsson's model being a viscoelastic model of stress transmission and this model being a hydrologic model without stress transmission. For the case of finite connectivity, the turbulent flow velocity $U$ takes the place of the viscoelastic relaxation speed of Gudmundsson (2011).

In this hydrologic model, we have essentially replaced the elastic and viscoelastic material parameters of Gudmundsson $(2007,2011)$ with till material and fluid flow parameters. If we take reasonable values of $\frac{\mathrm{d} H}{\mathrm{~d} x}=\frac{5 \mathrm{~m}}{10^{4} \mathrm{~m}}=0.0005, k=0.1 \mathrm{~m}$, and $R=0.1 \mathrm{~m}$, we find that $U \approx 0.2 \mathrm{~m} \mathrm{~s}^{-1}$. Taking $f \approx 0.2$, the observations from Rutford Ice Stream can be explained using our hydrologic model as well as the viscoelastic model of Gudmundsson (2011), but without the problems of elastic stress transmission discussed in the earlier sections of this paper. A more precise evaluation of this hydrologic model, such as including the effect of the decay of fluid pressure perturbation upstream, is beyond the scope of this paper but could provide a method for constraining basal friction and hydrologic connectivity using the observed decay of tidal stresses on Antarctic ice streams.

\section{Conclusions}

From our modeling, we find the following:

1. For models supported either at the bed or at the margins, an axially applied tidal load decays exponentially with 
distance inland of the grounding line. Furthermore, for a reasonable elastic or viscoelastic model, this decay is too severe to transmit stresses far enough inland to explain surface observations from Rutford Ice Stream, an archetypical narrow ice stream.

2. The ice shelf and the resulting flexural stresses are important close to the grounding line but can be neglected when considering the effects of tidal loading many tens of kilometers inland of the grounding line.

3. An ice stream with compliant lateral margins transmits tidal stresses farther inland than a homogeneous elastic ice stream in a nonlinear fashion. Using a linear damage mechanics model, we find that we would need damage resulting in upwards of a $99.9 \%$ reduction in Young's modulus to rectify model results with observations.

4. A Glen-style viscoelastic rheology using canonical values and a realistic temperature profile does not change the inland transmission of stress in a meaningful fashion.
Our modeling demonstrates the importance of an ice stream's lateral margins' control on the behavior of an ice stream under the influence of a tidal load. We are unable to reproduce observations of inland transmission of tidal stresses from Rutford Ice Stream using a reasonable set of elastic or viscoelastic parameters when the finite width of the ice stream is included in our models.

Since we could not match observations using an elastic or viscoelastic 3-D model of a tidally loaded ice stream, we present a 2-D flow-line model for the inland transmission of a tidal perturbation through the fluid pressure in subglacial till. Using reasonable material parameters, we demonstrated that this model can reproduce the modeling results of Gudmundsson (2011) for Rutford Ice Stream's tidally modulated motion without the transmission of tidal stress through the ice stream itself. Thus, we conclude that for narrow (channelized) ice streams like Rutford Ice Stream the observed influence of ocean tides on the motion of ice streams can be caused by the tidal modulation of the subglacial hydrologic network rather than the direct transmission of tidal stresses through the bulk of an ice stream. 


\section{Appendix A: Importance of the ice shelf}

Since the Antarctic ice streams discussed in this manuscript have a connected ice shelf, we now consider the role that the ice shelf plays as an intermediary between the ocean tides and the grounded ice stream. Recall the 2-D model results shown in Figs. 3 and 4 for models with and without an ice shelf. For a given basal condition, variations between the two model results must be due to the presence of the shelf as all other boundary conditions are kept constant (see Sect. 2.2).

For 2-D models with a frozen bed, the presence of an ice shelf has two effects. First, there are flexural stresses introduced by the ice shelf that are limited to approximately two ice thicknesses of the grounding line. Second, the overall magnitude of stresses in the ice stream is elevated compared to models without an ice shelf. However, neither effect changes $L_{\text {tr }}$ between the two models. The presence of an ice shelf in these models affects the magnitude, but not the decay, of non-flexural tidal stresses inland of the grounding line.

For 2-D models with a free-sliding bed, the flexural stresses decay to inconsequential levels about six ice thicknesses inland of the grounding line. Beyond this point, the stress state of the ice stream is identical to the stress state for a model with axial loading only. In the absence of basal resistance, the presence of an ice shelf does not affect the magnitude or decay of non-flexural tidal stresses within the grounded ice stream.

The general result of flexural stresses only perturbing the stress field near the grounding line is consistent with realworld observations that limit ice flexure to $10 \mathrm{~km}$ inland of the grounding line (Table 1). Additionally, as described in Appendix B, the constant-stress condition used in our models to represent the ocean tide overestimates flexural stress by almost a factor of 4 compared to a more realistic floating condition, suggesting that flexural stresses may decay to inconsequential values over shorter distance than predicted by our models. Based on our models and observational data, tidally induced flexural stresses are not expected to be sizable components of the tidal stresses found far inland of the grounding line and, thus, can be neglected in our 3-D models.

However, our models show that the presence of an ice shelf can influence the magnitude of non-flexural tidal stresses seen inland of the ice stream's grounding line for models with basal resistance. As described earlier, the addition of an ice shelf to the model with a frozen bed increases the equivalent (tidal) stress throughout the ice stream by about an order of magnitude compared to a model without an ice shelf (Fig. 4). This increased stress magnitude is not seen in models with a free-sliding bed (Fig. 3). As ice streams have little basal resistance, we expect our 3-D models will behave more like the free-sliding bed than the frozen-bed end-member 2-D model. We do not expect the presence of an ice shelf in our 3-D models to influence the magnitude of non-flexural tidal stresses inland of the grounding line. Ultimately, as our 2-D models show that the ice shelf does not change $L_{\text {tr }}$ for a given model and is unlikely to change the magnitude of the non-flexural stresses inland of the grounding line, we choose to neglect the ice shelf in our 3-D models.

\section{Appendix B: Analysis of the flotation condition for a one- dimensional ice shelf}

As shown in Fig. 2, we apply normal tractions to the $X+$ and $Z$ - edges of the model ice shelf to simulate the stress due to a change in tide height. First, we consider the axial load of the tide on the ice shelf's $X+$ edge. A 1-D analog is a bar that is axially compressed by a constant stress. Take the bar as fixed at the unforced end. By the compatibility condition,

$\delta \sigma / \delta x=0$.

The stress and strain in such a model must be constant throughout the bar; that is, the stress transmission is infinite.

Second, we consider the flotation condition on the ice shelf (i.e., the stress applied to the $Z$ - edge of the ice shelf). We take a 1-D analog using a Bernoulli-Euler beam subjected to a distributed load coupled to the beam deflection by a flotation condition. This approach is similar to the methodology of Reeh et al. (2000). The governing equation of such a model is

$E I \frac{\delta^{4} w}{\delta x^{4}}=\rho_{\mathrm{W}} g(\Delta h-w)$,

where $\rho_{\mathrm{W}}$ is the density of water, $g$ is gravitational acceleration, $w$ is the (vertical) deflection of the beam, $E$ is the Young's modulus of ice, $I=\left(\frac{w}{12}\right) \times\left(H_{\mathrm{I}}\right)^{3}$ is the second moment of area for the ice shelf, and $H_{\mathrm{I}}$ is ice thickness. At the grounding line $(x=0)$, the beam is "clamped" $\left(w=\frac{\delta w}{\delta x}=0\right)$ and the freeboard edge is "free" $\left(\frac{\delta^{2} w}{\delta x^{2}}=\frac{\delta^{3} w}{\delta x^{3}}=0\right)$.

The solutions of Eq. (B2) for multiple ice shelf lengths are shown in Fig. B1. The primary result is that, for a $1 \mathrm{~m}$ tide and an ice thickness of $1 \mathrm{~km}$, increasing the length of the beam beyond $5 \mathrm{~km}$ no longer influences the stresses at the grounding line, suggesting that we only need to consider a shelf several ice thicknesses long in our finite-element models.

Additionally, we model a linearly thinning ice shelf (through the modification of $I$, using $I=\left(\frac{w}{12}\right) \times$ $\left(\left[h_{0}-\left(h_{0}-h_{1}\right)\right] \frac{X}{L}\right)^{3}$, where the thickness linearly changes from $h_{0}$ to $h_{1}$ ) and find that this only has a small influence on the stress and deflection throughout the shelf. The effects of ice shelf thinning will not be considered further.

Lastly, we model the results for a simpler, uncoupled stressing condition. In Fig. B1, the red dashed line corresponds to a constant loading function equal to $\rho_{\mathrm{W}} g \Delta h$ (the "constant loading function"). This simpler condition overestimates the stress and deflection over the model domain compared to the more correct flotation condition. However, as the 

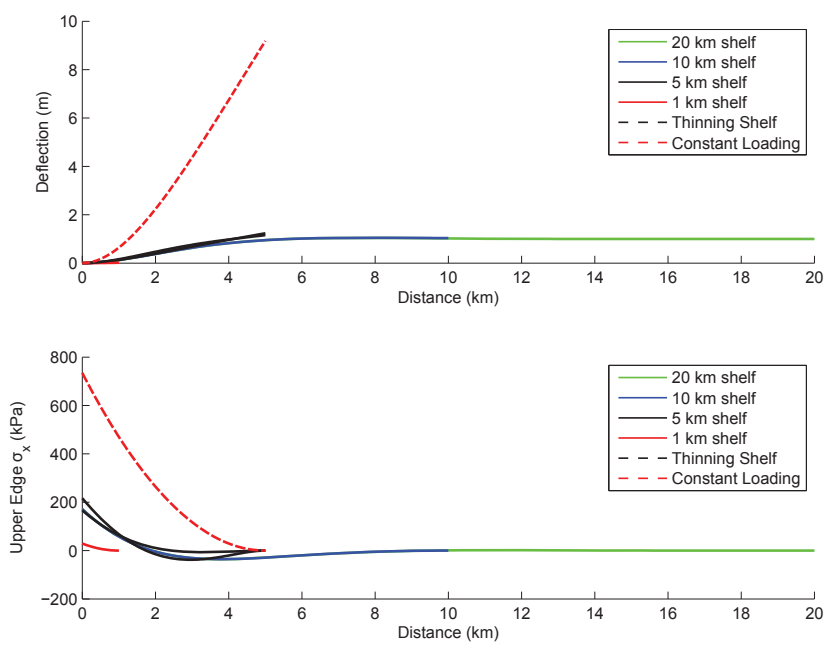

Figure B1. Results of the 1-D flexural beam approximation of a floating ice shelf. The upper figure shows the beam deflection, while the lower section shows the stress at the upper edge of the beam. See text in Appendix B for a description of the governing equations and boundary conditions for the models shown.

boundary condition is decoupled from the deflection $w$, we can directly use this constant loading as a "pseudo-flotation" condition on the $Z$ - edge of our finite-element ice shelf. The result of this simplification is that the flexural stresses induced by the ice shelf will be overestimated at the grounding line in our 2-D finite-element models.

\section{Appendix C: Viscoelastic tidal loading}

Following the rationale of Cuffey and Paterson (2010) (and references therein), the full stress balance for an ice stream-shelf system should involve balancing the hydrostatic pressure at the edge of the ice shelf and that of the ocean. Since the ice shelf is floating, there is a net "pull" on the ice stream due to excess pressure in the ice shelf compared to that of the ocean. As ice viscosity is stress-dependent, we need to account for this end stress in our models to accurately model the viscous deformation in the ice stream. However, our viscoelastic models are more numerically tractable with a simple oscillatory tidal condition based solely on the change in ocean tidal height because a larger stable time step is allowed and model convergence is faster. Thus, we compare the model output for these two tidal loading conditions, referred to as "full" and "simple", to determine whether our simple tidal condition adequately approximates the full tidal condition. We find that having the more complex full tidal condition changes $L_{\text {tr }}$ by only about $20 \%$, far below the factor of 2 to 4 change necessary to match observations. We use this result as justification for using the more numerically favorable simple tidal condition.

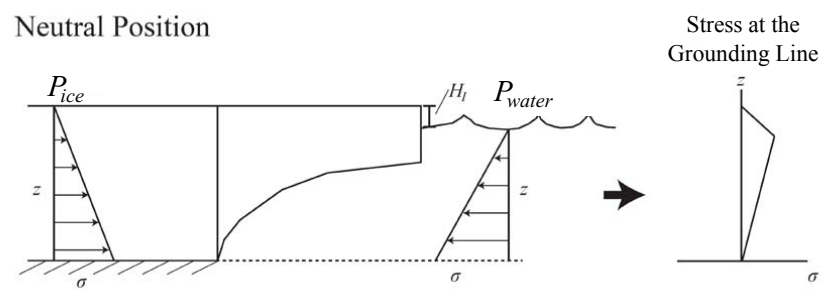

High Tide
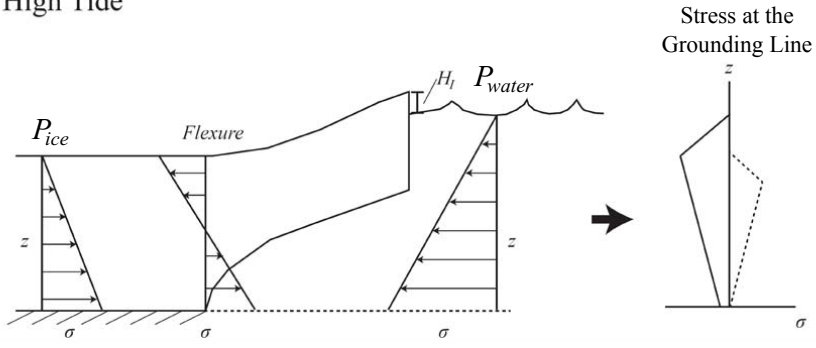

Low Tide

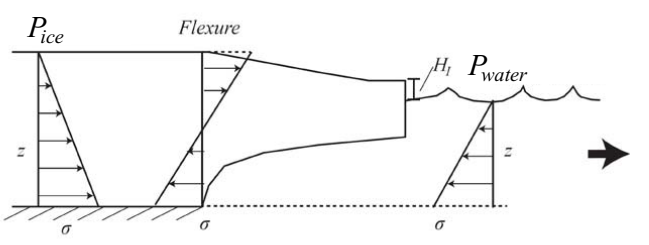

Stress at the Grounding Line

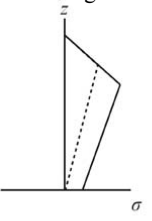

Figure C1. Schematic diagrams of the full tidal forcing condition at a neutral, high, and low tide. The tidal stress will be the extensional/compressional stress due to the difference in hydrostatic pressure at the edge of the ice shelf (shown in the graph on the right of the figure) and the flexural stresses due to the presence of the ice shelf. $H_{\mathrm{I}}$ is the distance between the surface of the ice shelf and the surface of the ocean.

\section{C1 Full tidal loading condition}

In addition to the oscillatory load of the ocean tide, there are other stresses at the grounding line that a full tidal loading condition needs to consider. These stresses include the hydrostatic pressure of the flowing ice, the hydrostatic pressure of the static ocean water, and the flexural stress imposed on the grounding line due to the vertical motion of the ice shelf. Figure $\mathrm{C} 1$ shows a schematic picture of the interaction of these stresses on an ice stream at neutral, high, and low tides.

First consider the hydrostatic pressures of the ice and the water. For the ice, the hydrostatic stress at a depth $z$ is $\rho_{\mathrm{I}} g\left(H_{\mathrm{I}}-z\right)$, where $\rho_{\mathrm{I}}$ is ice density, $g$ is gravitational acceleration, and $H_{\mathrm{I}}$ is the ice thickness. For the water, we first use the condition that an ice stream is neutrally buoyant at the grounding line to find that the average water level of the ocean is $H_{T}=H_{\mathrm{I}}\left(1-\rho_{\mathrm{I}} / \rho_{\mathrm{W}}\right)$, where $\rho_{\mathrm{W}}$ is the density of water. This flotation condition is used to find that hydrostatic pressure of the ocean at $0 \leq z \leq H_{T}$ is $\rho_{\mathrm{W}} g\left(H_{T}-z\right)$. However, this stress balance occurs across the edge of the ice shelf, not at the grounding line. By assuming that viscous deformation of the ice shelf is negligible, the results from 
our 2-D shelf models (Sect. 3.1) allow us to move this stress balance to the grounding line.

To account for the bending stress from ice flexure, we use the simple beam theory presented in Appendix B. From this simple model for flexure, we expect that the flexural stress at the grounding line will be on the order of a few $100 \mathrm{kPa}$ at a maximum (with the exact value dependent on the ice thickness and the geometry of the ice shelf).

The full load applied at the grounding line is the sum of these stresses. Figure $\mathrm{C} 1$ shows a graphical representation of these tidal loads described by Eq. (C1):

$$
\begin{aligned}
\sigma_{\text {applied }}(z) & =\left\{\begin{array}{ll}
-\rho_{\mathrm{I}} g\left(H_{\mathrm{I}}-z\right) \\
-\rho_{\mathrm{I}} g\left(H_{\mathrm{I}}-z\right)+\rho_{\mathrm{W}} g\left(H_{T}-z\right) & \text { if } z \leq H_{T}
\end{array}\right\} \\
& +\sigma_{\text {flex }}(t)\left(\frac{2 z}{H_{\mathrm{I}}}-1\right)+\rho_{\mathrm{W}} g \Delta h(t),
\end{aligned}
$$

where $\sigma_{\text {flex }}$ is the maximum amplitude of flexural stress induced at the grounding line. For a reasonable tidal loading, the maximum force comes from the static pull, which is on the order of $1 \mathrm{MPa}$ at the base of a $1 \mathrm{~km}$ thick ice stream, while the flexural stress is a few hundred $\mathrm{kPa}$ and the change in tidal weight is a few tens of $\mathrm{kPa}$.

\section{C2 Simple tidal loading condition}

For the simple loading condition, we apply the variable portion of the ocean tidal load as a normal traction to the grounding line. Mathematically, this condition is

$\sigma_{\text {applied }}=\rho_{\mathrm{W}} g \Delta h(t)$.

This is identical to the approach taken in our linear elastic models, except that the applied stress is time-variable. The time dependence of this condition is described in Sect. 5.1.

\section{C3 Stress transmission comparison}

Figure $\mathrm{C} 2$ shows a comparison between the tidally induced $\sigma_{y y}$ component of stress for a map view of the base of a model with the full (left panel) and simple (right panel) loading conditions taken at a peak in stress response. We first note that, overall, the stress field is remarkably similar between the full and simple loading conditions. The only major difference occurs in the portion of the ice stream near the grounding line, where the full loading condition has higher stress values than those of the simple loading model. Such an increase in the value of the stress near the grounding line in the full model is not surprising as the value of the applied load is larger in this model than with the simple loading condition. However, farther inland, the stresses in the models are nearly indistinguishable. The increased stress at the grounding line causes an increase in $L_{\text {tr }}$ for the full tidal loading model of approximately $20 \%$, suggesting that the hydrostatic pull on the ice stream edge and ice shelf flexure do not influence ice viscosity enough to significantly change the value of $L_{\mathrm{tr}}$.

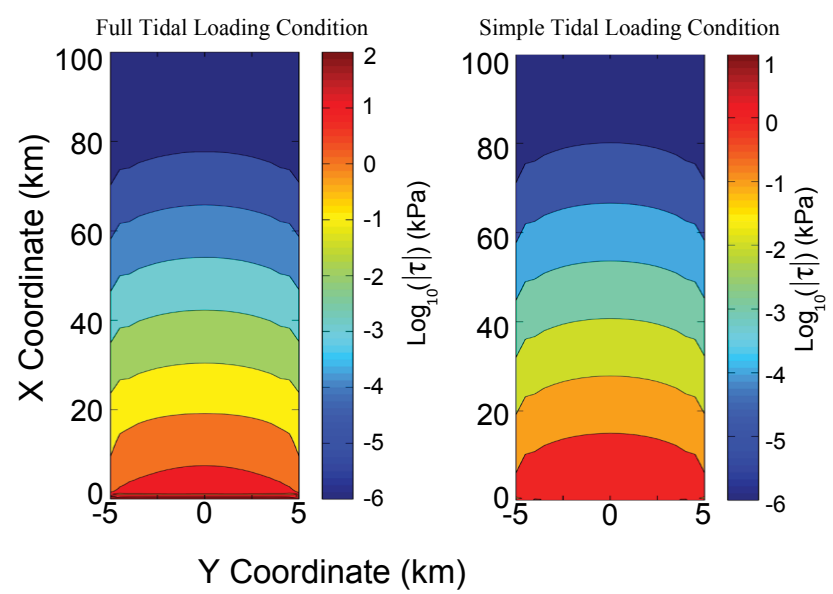

Figure C2. Comparison of the value of the longitudinal normal stress $\left(\sigma_{x x}\right)$ for the full tidal forcing condition (left panel) and the partial tidal forcing condition (right panel) at peak tidal amplitude. The full condition has a higher normal stress at the grounding line and a slightly more rapid decay of the stress due to the inclusion of the flexural stress. Once inland of the grounding line by 5 to $10 \mathrm{~km}$, the stress-transmission length scales are comparable between the two forcing conditions.

As the difference between $L_{\mathrm{tr}}$ in the models explored here is only about $20 \%$, we feel safe in neglecting the full tidal loading condition in our viscoelastic models. In order to match observations with our models, $L_{\text {tr }}$ needs to increase by a factor of 2 to 4 from the elastic models (see Sect. 3.4). Given the other model simplifications and assumptions, the slight gain in model accuracy is not worth the increased complexity (and thus computation time) of using the full loading condition. 
Acknowledgements. The authors would like to thank the two anonymous reviewers of this manuscript and editor Oliver Gagliardini for their constructive comments. We would also like to thank J. N. Bassis and Martin Lüthi for their constructive review of an earlier version of this manuscript. Part of this research was carried out at the Jet Propulsion Laboratory and the California Institute of Technology under a contract with the National Aeronautics and Space Administration and funded through the President's and Director's Fund Program.

Edited by: O. Gagliardini

\section{References}

Aagaard, B., Williams, C., and Knepley, K.: PyLith: A finiteelement code for modeling quasi-static and dynamic crustal deformation, Eos Trans. AGU, 88, Fall Meet. Suppl., Abstract T21B-0592, 2007.

Aagaard, B., Williams, C., and Knepley, M.: PyLith: A finiteelement code for modeling quasi-static and dynamic crustal deformation, Eos Trans. AGU, 89, Fall Meet. Suppl., Abstract T41A-1925, 2008.

Aagaard, B., Kientz, S., Knepley, M., Somala, S., Strand, L., and Williams, C.: PyLith User Manual, Version 1.6.0, Computational Infrastructure of Geodynamics, Davis, CA, geodynamics.org/cig/software/pylith/pylith_manual-1.6.pdf (last access: 30 May 2013), 2011.

Adalgeirsdottir, G., Smith, A. M., Murray, T., King, M. A., Makinson, K., Nicholls, K. W., and Behar, A. E.: Tidal influence on Rutford Ice Stream, West Antarctica: observations of surface flow and basal processes from closely spaced GPS and passive seismic stations, J. Glaciol., 54, 715-724, 2008.

Alley, R. B., Blankenship, D. D., Bentley, C. R., and Rooney, S. T.: Deformation of till beneath Ice Stream B, West Antarctica, Nature, 322, 57-59, 1986.

Anandakrishnan, S. and Alley, R. B.: Tidal forcing of basal seismicity of ice stream C, West Antarctica, observed far inland, J. Geophys. Res., 102, 183-196, 1997.

Anandakrishnan, S., Voigt, D. E., Alley, R. B., and King, M. A.: Ice stream D flow speed is strongly modulated by the tide beneath the Ross Ice Shelf, Geophys. Res. Lett., 30, 1361, doi:10.1029/2002GL016329, 2003.

Balay, S., Gropp, W. D., McInnes, L. C., and Smith, B. F.: Efficient Management of Parallelism in Object Oriented Numerical Software Libraries, in: Modern Software Tools in Scientific Computing, edited by: Arge, E., Bruaset, A. M., and Langtangen, H. P., Birkhauser Press, Boston, 163-202, 1997.

Balay, S., Brown, J., Buschelman, K., Gropp, W. D., Kaushik, D., Knepley, M. G., McInnes, L. C., Smith, B. F., and Zhang, H.: PETSc Webpage, mcs.anl.gov/petsc (last access: 30 May 2013), 2012a.

Balay, S., Brown, J., Buschelman, K., Eijkhout, V., Gropp, W. D., Kaushik, D., Knepley, M. G., McInnes, L. C., Smith, B. F., and Zhang, H.: PETSc Users Manual, ANL-95/11 - Revision 3.3, Argonne National Laboratory, Lemont, 2012b.

Bathe, K.-J.: Finite-Element Procedures, Prentice Hall, Upper Saddle River, NJ, 1037 pp., 1995.
Bindschadler, R. A., Vornberger, P. L., King, M. A., and Padman, L.: Tidally driven stick-slip motion in the mouth of Whillans Ice Stream, Antarctica, Ann. Glaciol., 36, 263-272, 2003.

Borstad, C. P., Khazendar, A., Larour, E., Morlighem, M., Rignot, E., Schodlock, M. P., and Seroussi, H.: A damage mechanics assessment of the Larsen B ice shelf prior to collapse: Towards a physically-based calving law, Geophys. Res. Lett., 39, L18502, doi:10.1029/2012GL053317, 2012.

Brunt, K. M., Fricker, H. A., Padman, L., Scambos, T. A., and O'Neel, S.: Mapping the grounding zone of the Ross Ice Shelf, Antarctica, using ICESat laser altimetry, Ann. Glaciol., 51, 71-79, 2010.

Cuffey, K. M. and Paterson, W. S. B.: The Physics of Glaciers, 4th Edn., Elsevier, San Diego, CA, 693 pp., 2010.

Dahl-Jensen, D. and Gundestrup, N. S.: Constitutive properties of ice at Dye 3, Greenland, Int. Assoc. Hydrol. Sci., 170, 31-43, 1987.

Duddu, R. and Waisman, H.: A temperature dependent creep damage model for polycrystalline ice, Mech. Mat., 46, 23-41, 2012.

Echelmeyer, K. A. and Zhongxiang, W.: Direct observations of basal sliding and deformation of basal drift at sub-freezing temperatures, J. Glaciol., 33, 83-98, 1987.

Echelmeyer, K. A., Harrison, W. D., Larson, C., and Mitchell, J. E.: The role of the margins in the dynamics of an active ice stream, J. Glaciol., 40, 527-538, 1994.

Engelhardt, H.: Thermal regime and dynamics of the West Antarctic ice sheet, Ann. Glaciol., 39, 85-92, 2004a.

Engelhardt, H.: Ice temperature and high geothermal flux at Siple Dome, West Antarctica, from borehole measurements, J. Glaciol., 50, 251-256, 2004b.

Engelhardt, H. and Kamb, W. B.: Vertical temperature profile of Ice Stream B, Antarct. J. Rev., 1993, 63-66, 1993.

Engelhardt, H. and Kamb, W. B.: Basal sliding of Ice Stream B, West Antarctica, J. Glaciol., 44, 223-230, 1998.

Engelhardt, H., Humphrey, N., Kamb, B., and Fahnestock, M.: Physical conditions at the base of a fast moving Antarctic ice stream, Science, 248, 57-79, 1990.

Gammon, P. H., Kiefte, H., and Clouter, M. J.: Elastic-constants of ice samples by Brillouin spectroscopy, J. Phys. Chem., 87 , 4025-4029, doi:10.1021/j100244a004, 1983a.

Gammon, P. H., Kiefte, H., Clouter, M. J., and Denner, W. W.: Elastic-constants of artificial and natural ice samples by Brillouin Spectroscopy, J. Glaciol., 29, 433-460, 1983b.

Goodier, J. N.: An extension of Saint-Venant's Principle, with applications, J. Appl. Phys., 13, 167-171, 1942.

Gudmundsson, G. H.: Fortnightly variations in the flow velocity of Rutford Ice Stream, West Antarctica, Nature, 444, 1063-1064, doi:10.1038/nature05430, 2006.

Gudmundsson, G. H.: Tides and the flow of Rutford Ice Stream, West Antarctica, J. Geophys. Res., 112, F04007, doi:10.1029/2006JF000731, 2007.

Gudmundsson, G. H.: Ice-stream response to ocean tides and the form of the basal sliding law, The Cryosphere, 5, 259-270, doi:10.5194/tc-5-259-2011, $2011 .$.

Harrison, W. D., Echelmeyer, K. A., and Engelhardt, H.: Shortperiod observations of speed, strain and seismicity on Ice Stream B, Antarctica, J. Glaciol., 39, 463-470, 1993. 
Heinert, M. and Riedel, B.: Parametric modelling of the geometrical ice-ocean interaction in the Ekstroemisen grounding zone based on short time-series, Geophys. J. Int., 169, 407-420, doi:10.1111/j.1365-246X.2007.03364.x, 2007.

Hetland, E. A. and Hager, B. H.: Postseismic and interseismic displacements near a strike-slip fault: A two-dimensional theory for general linear viscoelastic rheologies, J. Geophys. Res., 110, B10401, doi:10.1029/2005JB003689, 2005.

Hooke, R. L. and Hanson, B.: Borehole deformation experiments, Barnes Ice Cap, Canada, Cold Reg. Sci. Technol., 12, 261-276, 1986.

Hughes, T. J.: Ice Sheets, Oxford University Press, New York, NY, 343 pp., 1998.

Jellinek, H. H. G. and Brill, R.: Viscoelastic properties of ice, J. Appl. Phys., 27, 1198-1209, 1956.

Joughin, I., Bamber, J. L., Scambos, T., Tulaczyk, S., Fahnestock, M., and MacAyeal, D. R.: Integrating satellite observations with modeling: basal shear stress of the Flicher-Ronne ice streams, Antarctica, Philos. T. Roy. Soc. A, 364, 1785-1814, doi:10.1098/rsta.2006.1799, 2006.

Manning, R.: On the flow of water in open channels and pipes, Trans. Inst. Civil Eng., 20, 161-207, 1891.

Murakami, S.: Continuum damage mechanics: a continuum mechanics approach to the analysis of damage and fracture, Springer Science + Business Media, London, 402 pp., 2012.

Paterson, W. S. B.: Why ice-age ice is sometimes soft, Cold Reg. Sci. Technol., 20, 75-98, 1991.

Paterson, W. S. B.: The Physics of Glaciers, 3rd Edn., Pergamon, New York, 480 pp., 1994.

Petrenko, V. F. and Whitford, R. W.: Physics of Ice, 2nd Edn., Oxford University Press, Oxford, England, 2002.

Pralong, A. and Funk, M.: Dynamic damage model of crevasse opening and application to glacier calving, J. Geophys. Res.Solid, 110, B1309, doi:10.1029/2004JB003104, 2005.

Raymond Pralong, M. and Gudmundsson, G. H.: Bayesian estimation of basal conditions on Rutford Ice Stream, West Antarctica, from surface data, J. Glaciol., 57, 315-324, 2011.

Reeh, N., Mayer, C., Olesen, O. B., Christensen, E. L., and Thomsen, H. H.: Tidal movement of Nioghalvfjerdfjorden glacier, northeast Greenland: observations and modelling, Ann. Glaciol., 31, 111-117, 2000.

Riedel, B., Nixdorf, U., Heinert, M., Eckstaller, A., and Mayer, C.: The response of the Ekstromisen (Antarctica) grounding zone to tidal forcing, Ann. Glaciol., 29, 239-242, 1999.

Rignot, E. J.: Fast Recession of a West Antarctic Glacier, Science, 281, 549-551, doi:10.1126/science.281.5376.549, 1998.

Rosier, S. H. R., Gudmundsson, G. H., and Green, J. A. M.: Insights into ice stream dynamics through modelling their response to tidal forcing, The Cryosphere, 8, 1763-1775, doi:10.5194/tc8-1763-2014, 2014.

Scott, J. B. T., Gudmundsson, G. H., Smith, A. M., Bingham, R. G., Pritchard, H. D., and Vaughan, D. G.: Increased rate of acceleration on Pine Island Glacier strongly coupled to changes in gravitational driving stress, The Cryosphere, 3, 125-131, doi:10.5194/tc-3-125-2009, 2009.

Sergienko, O. V., MacAyeal, D. R., and Bindschadler, R. A.: Stick-slip behavior of ice streams: modeling investigations, Ann. Glaciol., 50, 87-94, 2009.
Smith, A. M.: Basal conditions on Rutford Ice Stream, West Antarctica, from seismic observations, J. Geophys. Res., 102, 543-552, 1997.

Stephenson, S. N.: Glacier flexure and the position of grounding lines: measurements by tiltmeter on Rutford Ice Stream, Antarctica, Ann. Glaciol., 5, 165-169, 1984.

Timoshenko, S. P. and Goodier, J. N.: Theory of Elasticity, 3rd Edn., McGraw-Hill Book Company, San Francisco, C.A., 567 pp., 1982.

Tsai, V. C. and Rice, J. R.: A model for turbulent hydraulic fracture and application to crack propagation at glacier beds, J. Geophys Res., 115, F03007, doi:10.1029/2009JF001474, 2010.

Tulaczyk, S., Kamb, B., and Engelhardt, H. F.: Basal mechanics of Ice Stream B, West Antarctica, 1. Till mechanics, J. Geophys. Res., 105, 463-481, 2000.

Turcotte, D. L. and Schubert, G.: Geodynamics, 2nd Edn., Cambridge University Press, Cambridge, UK, 456 pp., 2002

Walker, R. T., Christianson, K., Parizek, B. P., Anandakrishnan, S., and Alley, R. B.: A viscoelastic flowline model applied to tidal forcing of Bindschadler Ice Stream, West Antarctica, Earth Plant. Sc. Lett., 319-320, 128-132, 2012.

Walsh, J. B.: The Effect of Cracks on the Uniaxial Elastic Compression of Rocks, J. Geophys. Res., 70, 399-411, 1965.

Walter, J. I, Brodsky, E. E., Tulaczyk, W., Schwartz, S. Y., and Pettersson, R.: Transient slip events from near-field seismic and geodetic data on a glacier fault, Whillans Ice Plain, West Antarctica, J. Geophys. Res., 116, F01021, doi:10.1029/2010JF001754, 2011.

Weertman, J.: On the sliding of glaciers, J. Glaciol., 3, 33-38, 1957.

Weertman, J.: The theory of glacier sliding, J. Glaciol., 5, 287-303, 1964.

Weertman, J.: Creep deformation of ice, Ann. Rev. Earth Planet. Sci., 11, 215-240, 1983.

Wiens, D. A., Anandakrishnan, S., Winberry, J. P., and King, M. A.: Simultaneous teleseismic and geodetic observations of the stickslip motion of an Antarctic ice stream, Nature, 453, 770-775, doi:10.1038/nature06990, 2008.

Williams, C. A.: Development of a package for modeling stress in the lithosphere, Eos Trans. AGU, 87, Jt. Assem. Suppl., Abstract T24A-01 Invited, 2006.

Williams, C. A., Aagaard, B., and Knepley, M. G.: Development of software for studying earthquakes across multiple spatial and temporal scales by coupling quasi-static and dynamic simulations, Eos Trans. AGU, 86, Fall Meet. Suppl., Abstract S53A1072, 2005.

Winberry, J. P., Anandakrishnan, S., Alley, R. B., Bindschadler, R. A., and King, M. A.: Basal mechanics of ice streams: Insights from the stick-slip motion of Whillans Ice Stream, West Antarctica, J. Geophys. Res., 114, F01016, doi:10.1029/2008JF001035, 2009.

Winberry, J. P., Anandakrishnan, S., Alley, R. B., Wiens, D. A., and Pratt, M. J.: Tidal pacing, skipped slips and the slowdown of Whillans Ice Stream, Antarctica, J. Glaciol., 60, 222, 795-807, doi:10.3189/2014JoG14J038, 2014. 